University of Redlands

\title{
ArcGIS Tool Implementation of Risk Terrain Modeling
}

A Major Individual Project submitted in partial satisfaction of the requirements

for the degree of Master of Science in Geographic Information Systems

by
Sara Lavon Goetz

Fang Ren, Ph.D., Committee Chair

Mark Kumler, Ph.D.

August 2012 
ArcGIS Tool Implementation of Risk Terrain Modeling

Copyright (C) 2012

by

Sara Lavon Goetz 
The report of Sara Lavon Goetz is approved.

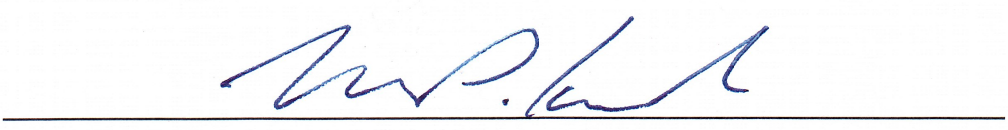

Mark Kumler, Ph.D.

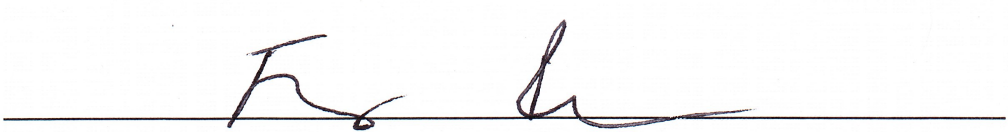

Fang Ren, Ph.D., Committee Chair

August 2012 



\section{Acknowledgements}

There are many whom I would like to thank for their support throughout my year at the University of Redlands. First, I thank God for the opportunity to attend this program, and for carrying me through it.

I thank my husband for his support and encouragement in my quest for a master's degree from the other side of the country; for using all of his vacation days and countless hours sitting in the airport; and for turning mountains that I made from molehills back into molehills.

I also thank my advisor, Dr. Fang Ren, for her skillful guidance through this project and the rest of the MS GIS faculty for their support of my project. Skills that I learned from each faculty member directly influenced and made possible different sections of my project. I also thank my client, Phil Mielke, for his encouragement and flexibility throughout the project, especially as my project scope narrowed down.

I thank my classmates-who quickly became friends-for their mutual support and guidance in navigating through this challenging program. I especially thank my friend, gym buddy, and classmate Amanda for always knowing what to say when stress reached near-meltdown levels, and for all of the hilariously fun times we have shared this year. I also thank my friends and family back home for their support throughout the year. 



\author{
Abstract \\ ArcGIS Tool Implementation of Risk Terrain Modeling \\ by \\ Sara Lavon Goetz
}

This project implements the Risk Terrain Modeling (RTM) method in an ArcGIS tool in order to make predictive crime modeling more practical for the Redlands, California Police Department. Residential burglaries in Redlands are used as a case study to demonstrate tool capability and validity. Factors found to be correlated with the occurrence of residential burglary are modeled as raster surfaces. These factors are combined within the RTM tool and assigned weights that correspond to their influence on the model. A binary logistic regression test indicated that the model produced a statistically significant output. 



\section{Table of Contents}

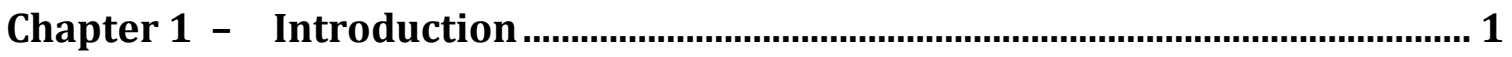

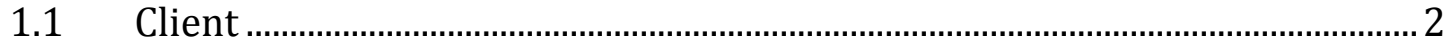

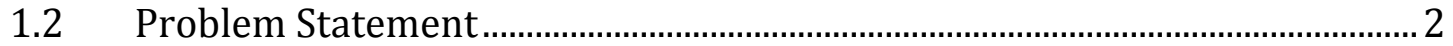

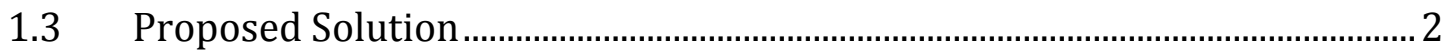

1.3.1 Goals and Objectives ………………………………………………………..

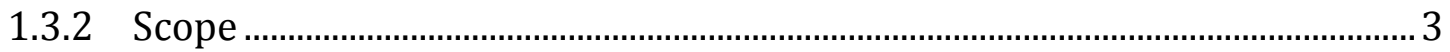

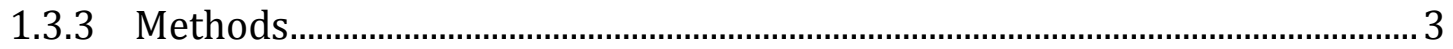

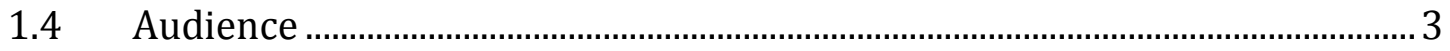

1.5 Overview of the Rest of this Report ..................................................................

Chapter 2 - Background and Literature Review................................................. 5

$2.1 \quad$ Predictive Crime Modeling ...............................................................................

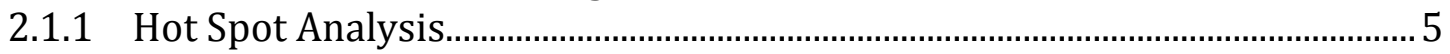

2.1.2 Leading Indicators ………………………………………………………... 6

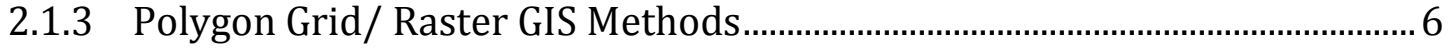

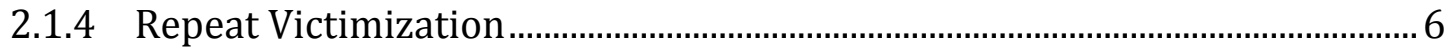

2.2 Risk Terrain Modeling ...................................................................................... 6

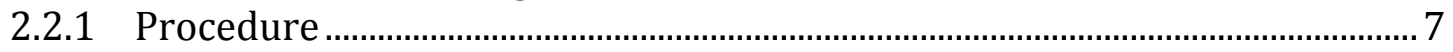

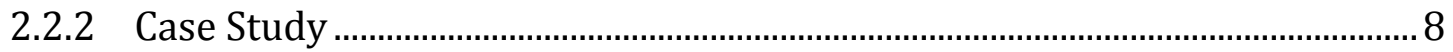

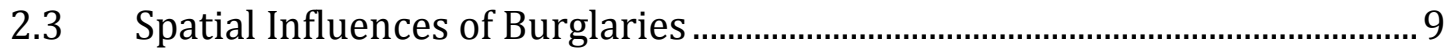

2.3.1 Proximity to High Schools...................................................................................

2.3.2 Accessibility ……………………………………………………………….. 10

2.3.3 Lighting and Surrounding Area ………………………………………….. 10

2.3.4 Social and Economic Indicators....................................................................... 11

2.3.5 Temporal Variation ....................................................................................... 11

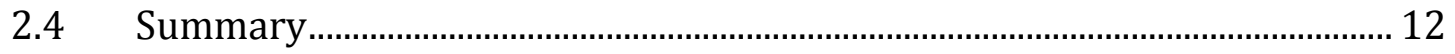

Chapter 3 - Systems Analysis and Design ………............................................13

$3.1 \quad$ Problem Statement........................................................................................ 13

3.2 Requirements Analysis .................................................................................. 13

3.2.1 Functional Requirements............................................................................ 14

3.2.2 Non-Functional Requirements..................................................................... 14

3.3 System Design ................................................................................................ 14

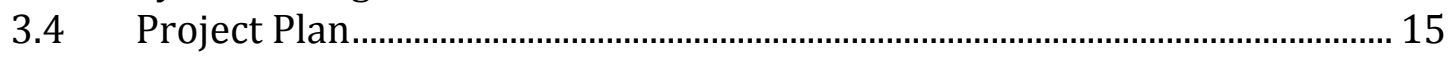

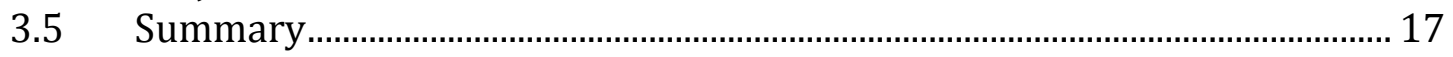

Chapter 4 - Database Design ..............................................................................19

4.1 Conceptual Data Model ............................................................................... 19

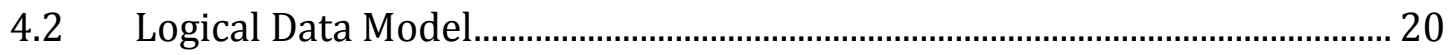

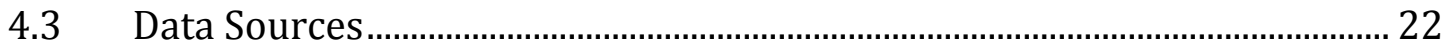

$4.4 \quad$ Data Scrubbing and Loading ........................................................................... 22

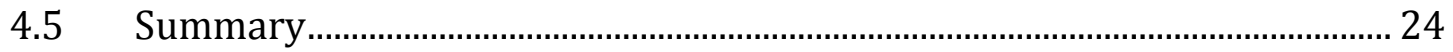

Chapter 5 - Implementation ….......................................................................25

$5.1 \quad$ Risk Factors' Operationalization ..................................................................... 25 


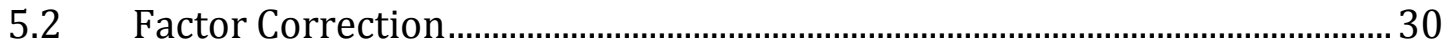

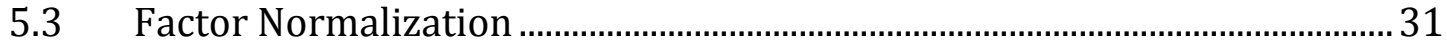

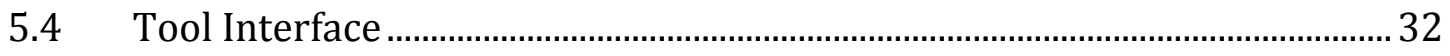

5.4.1 Crime Type Selection ........................................................................................ 32

5.4.2 Output Raster File ............................................................................................ 33

5.4.3 Mask Selection ............................................................................................ 33

5.4.4 Static Factor Selection ……………………………….......................................... 33

5.4.5 Dynamic Factor Selection .................................................................................. 34

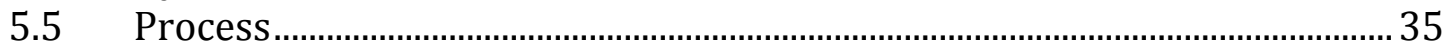

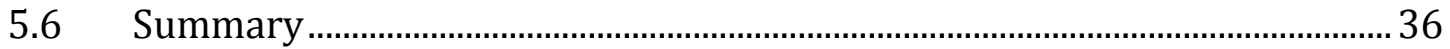

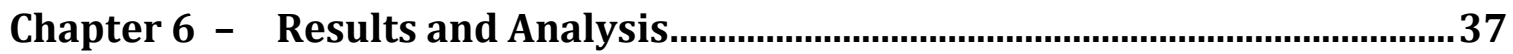

6.1 Chi-square Test.............................................................................................. 37

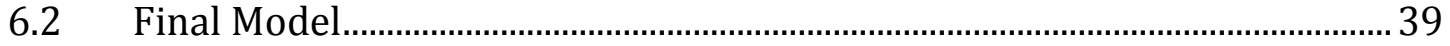

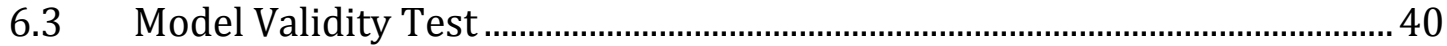

6.3.1 Output Preparation ................................................................................................ 40

6.3.2 Binary Logistic Regression Test....................................................................... 41

6.4 Discussion................................................................................................... 42

Chapter 7 - Conclusions and Future Work ……...................................................

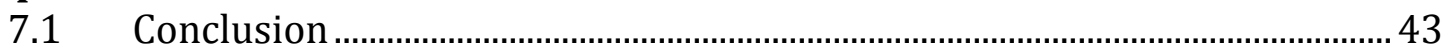

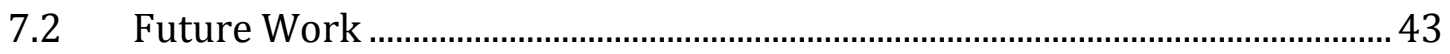

7.2.1 Incorporate Temporal Variables ………………………………………….... 43

7.2.2 Analysis of Other Crime Types ........................................................................ 43

7.2.3 Evaluating Police Patrol Effectiveness ............................................................... 44

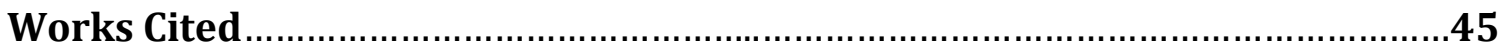

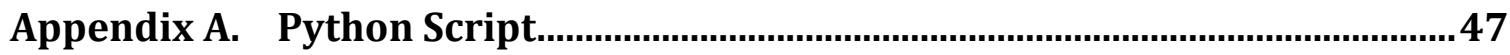

Appendix B. Detailed Chi-square Test Results................................................58

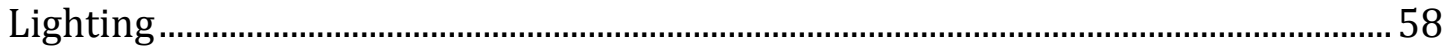

Proximity to Schools ................................................................................................ 58

Proximity to Groves or Vacant Lots .............................................................................. 59

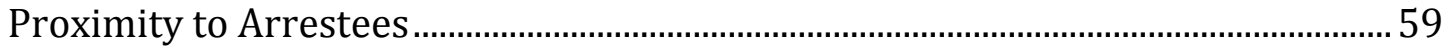

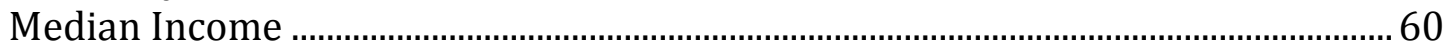

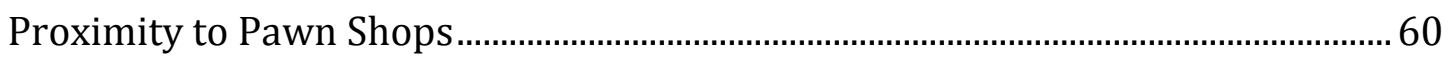

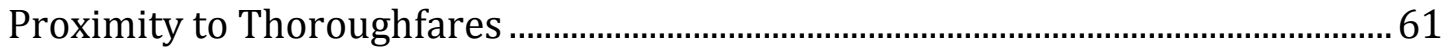

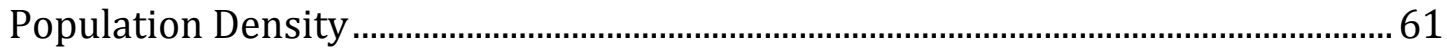

Household Density ....................................................................................................... 62 


\section{Table of Figures}

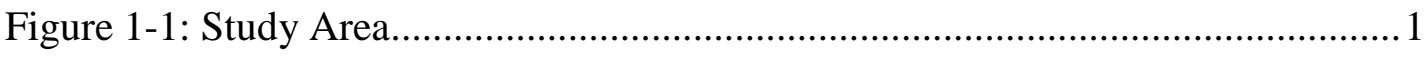

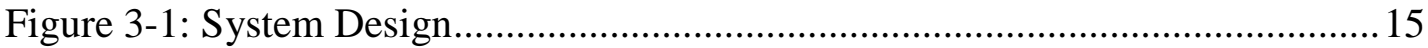

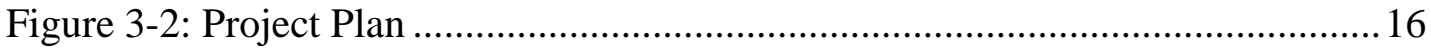

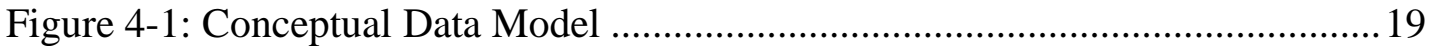

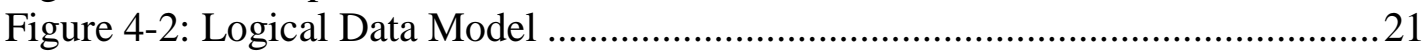

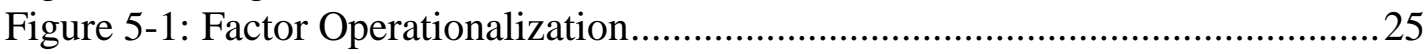

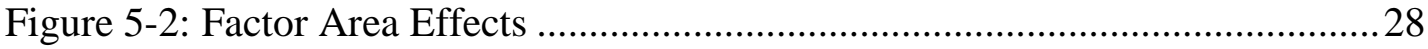

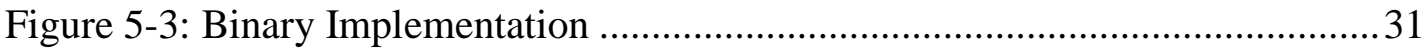

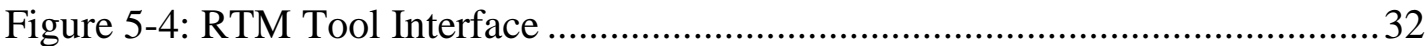

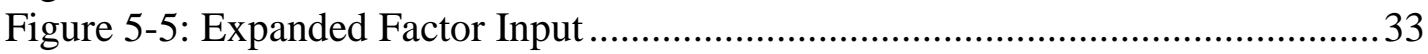

Figure 5-6: Expanded Dynamic Factor Selection ................................................... 34

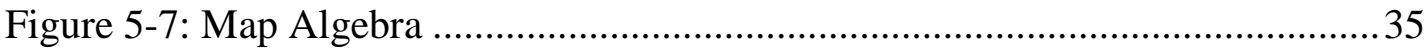

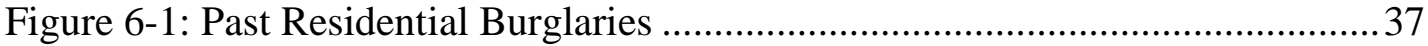

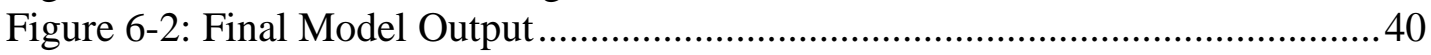

Figure 6-3: Output Preparation for Regression Test.......................................... 40 



\section{List of Tables}

Table 2-1: Risk Terrain Modeling Steps........................................................................ 7

Table 3-1: Functional and Non-Functional Requirements........................................... 13

Table 4-1: Potential Factors List for Residential Burglary ........................................... 20

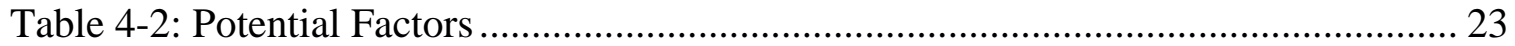

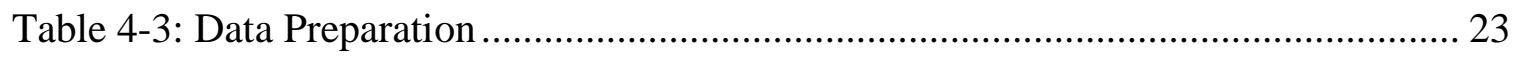

Table 5-1: Areal Effect Implementation ....................................................................... 26

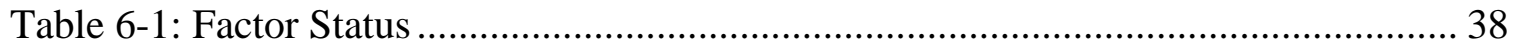

Table 6-2: Proximity to Freeway Access * Residential Burglary Crosstabulation .......... 38

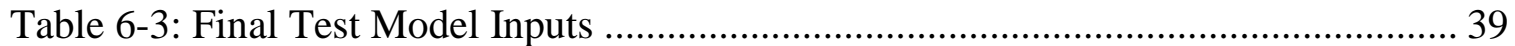

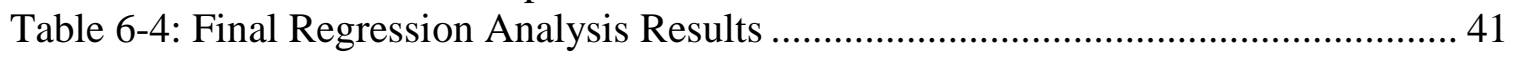




\section{List of Equations}

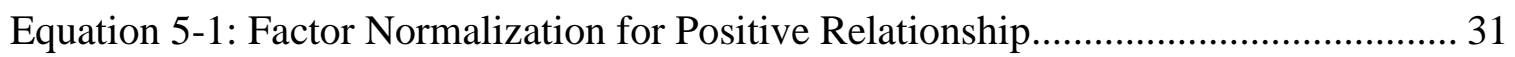

Equation 5-2: Factor Normalization for Negative Relationship ................................... 31 


\section{List of Acronyms and Definitions}

$\begin{array}{ll}\text { RTM } & \text { Risk Terrain Modeling } \\ \text { GIS } & \text { Geographic Information System } \\ \text { PD } & \text { Police Department }\end{array}$





\section{Chapter 1 - Introduction}

The City of Redlands (Figure 1-1) is located 60 miles east of Los Angeles, California, and is home to approximately 70,000 residents (U.S. Census Bureau, 2012). The Redlands Police Department employs approximately 75 (City of Redlands).

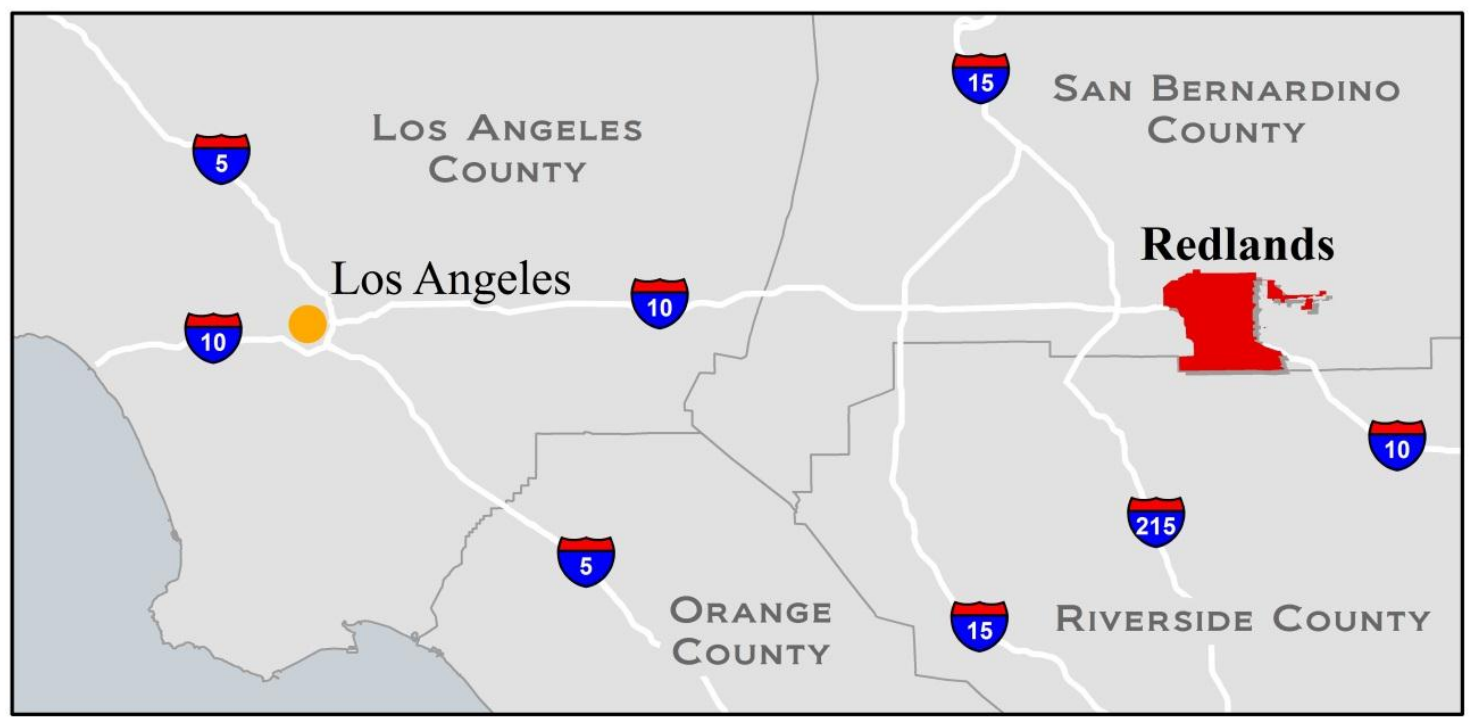

Figure 1-1: Study Area

As budgets for communities like Redlands shrink, it becomes necessary to reevaluate how sparse resources are allocated. The effectiveness of limited policing resources is one of the factors that a police department can examine to ensure that officers are serving where and when they are needed. Much of the police patrolling in Redlands is based on legacy patrol routes and individual officers' knowledge of the community (P. Mielke, personal communication, September 28, 2011). Because crime is dynamic over time, it can be difficult to keep patrols current with ongoing trends in the locations of crimes. Further, the Police Department collects a variety of geospatial data that have been underused on a daily basis for operational purposes. Thus, the Police Department was seeking a practical way to utilize these data to improve policing through the generation of a predictive crime model. The model would help the Police Department to better forecast where crimes are likely to occur in the future. However, for professionals trained in policing who do not have sufficient technical and analytical skills, the task of synthesizing all of the collected data is cumbersome and time consuming. To address the need of the police department, this project employs various datasets and crime incident data to produce a risk terrain model for residential burglary that will aid in accomplishing police department objectives. The predicted risk terrain allows quicker and easier identification of locations in need of additional support and will aid in maximizing allocation of limited policing resources.

Chapter 1 is organized as follows: Section 1.1 introduces the project client and the problem addressed in this project is discussed in Section 1.2. The proposed solution to the project problem is elaborated on in Section 1.3, and the intended audience for the project 
is described in Section 1.4. Section 1.5 provides an outline of the contents of the rest of the report.

\subsection{Client}

The client for this project was Mr. Phil Mielke, GIS Administrator for the City of Redlands, California. The client formerly worked for the City of Redlands Police Department (PD) as a GIS analyst and is well versed in the interworking of the police department.

The client provided all data needed for the project. A criminologist stationed at the City of Redlands PD helped to define the types of incidents that the police department wished to work with in the final product. The client and project team met as needed in order to track progress of the project, and to provide feedback.

The client and project lead had various shared and individual responsibilities. In order to create the risk model, factors influencing residential burglary were identified. The project team reviewed literature to better understand various factors associated with residential burglary. Ultimate responsibility for identifying which factors were considered for inclusion in the model fell on the client. The client provided almost all data for the project, with the exception of a dataset downloaded from the U.S. Census Bureau web site (www.censusbureau.gov). No field data collection was required.

\subsection{Problem Statement}

The City of Redlands was concerned that current police patrols may not be designed to maximize police influence on areas of the community where incidents are most likely to occur. Traditional threat models depicting crime "hot spots" in Redlands have been static. The city sought a predictive crime modeling tool to aid in predicting which areas of the city are at the most risk for a particular type of crime occurrence.

\subsection{Proposed Solution}

An Esri ArcGIS tool was created that allows supervisors at the City of Redlands Police Department to easily generate a predictive crime model for the city. The goals and objectives for the project are outlined in Section 1.3.1. The precise scope of this project is defined in Section 1.3.2. Specific methodologies employed to complete this project are presented in Section 1.3.3.

\subsubsection{Goals and Objectives}

The goal of this project was to aid the police department in predicting crime within the City of Redlands. To date, analysis of geospatial information collected by the department has been retrospective and static. The goal of the project was to create a risk terrain model (RTM) that can assist the Redlands PD to predict and visualize where crimes may occur based on a number of factors found to have an influence on the location of crime or incident occurrences. The model is presented in a tool that should be simple and easy for officers to understand in order to utilize the model on a daily, operational basis. 
The following objectives address the primary goal of aiding the City of Redlands PD in forecasting crime within the city. The first objective was to identify criminogenic factors to be considered as inputs into the model. The second project objective was to provide a predictive crime modeling tool with the following functionalities: input a variety of identified risk factors, assign weights to those factors, and implement the nearrepeats theory. The final objective is that the tool must be capable of adequately predicting areas most at risk of the crime type under study occurring.

\subsubsection{Scope}

The main project deliverable was a tool that the City of Redlands Police Department can use to easily visualize areas most at risk of crimes occurring. The tool was developed in the conceptual framework of risk terrain modeling to calculate and model the risk surface. Although the tool was specifically created for residential burglary, it is capable of producing predictive models of any number of crime types, provided crime-specific input factors are identified.

A geodatabase containing a set of rasterized risk layers representing factors found to be correlated to residential burglaries will also be provided to the client. These rasters are specifically formatted for residential burglaries, but may be utilized by the client in the future to build additional risk surfaces of residential burglaries using recent data (queried by the tool).

\subsubsection{Methods}

This project utilized risk terrain modeling in order to produce a risk prediction raster for the City of Redlands, CA. The tool does not show the user where the most crimes are currently occurring, but does show areas with increased risk of crime occurrence in the future based on a number of factors.

The surfaces and tool were created using ESRI ArcGIS software. Factors previously associated with residential burglaries were identified through literature review, tested for statistically significant correlation, and combined as outlined in the Risk Terrain Modeling Manual (Caplan \& Kennedy, 2010). The tool used to execute the model and create the output raster surfaces was constructed using PythonWin. Up to six factors (represented as rasters with values ranging from zero to one) are allowed as tool inputs. Two additional factors, near-repeats, and recent arrestee home addresses, may be selected as options bringing the total number of potential factors to eight. These factors are combined with optional corresponding weights input by the user and masked to areas in which the crime type being studied may potentially occur (optional input). The tool is tested for statistical validity using a regression test on the risk terrain modeling tool output.

\subsection{Audience}

The intended users for the tool are both the GIS Administrator for the City of Redlands, who is well-versed in GIS, and supervisors within the police department who may not be familiar with GIS or geoprocessing concepts utilized by the tool in the background. 
This document may also be used as a reference for GIS analysts at other police departments who are looking for ways to integrate predictive crime modeling, specifically Risk Terrain Modeling, into their crime analysis toolbox.

\subsection{Overview of the Rest of this Report}

The following chapters describe the processes required to complete this project. A literature review of various types of predictive crime mapping and factors that have been found to be correlated with residential burglaries are discussed in Chapter 2. Chapter 3 covers system analysis and design. Data preparation and geodatabase design are discussed in Chapter 4. The design and implementation of the potential risk factors and the Risk Terrain Modeling Tool are described in Chapter 5, with a review of the accuracy of the model in Chapter 6. Chapter 7 concludes the project and discusses potential future work. 


\section{Chapter 2 - Background and Literature Review}

Chapter 2 provides a review of pertinent literature considered while designing the project approach. Crime forecasting and various methods of predictive crime modeling are examined in Section 2.1. The predictive modeling method chosen by the client for use in this project, risk terrain modeling, is examined in detail in Section 2.2. Literature pertaining to residential burglary and the factors found to influence where burglaries occur is discussed in Section 2.3. Section 2.4 summarizes the findings of the literature review.

\subsection{Predictive Crime Modeling}

A number of different methods exist that seek to combine varying factors from the social and/or physical environment to model where certain crimes are most likely to occur in the future. This is predictive crime modeling. Most previous forms of crime modeling have been retrospective in nature, meaning that they compile data on where crimes have already occurred, in an effort to detect spatial patterns that may exist within the data (Groff \& La Vigne, 2002). GIS technology has made predicting, or forecasting, where crime is more likely to occur a reality (Groff \& La Vigne, 2002). While the practice of predictive crime modeling is still in its infancy, the technology and models will continue to evolve to produce ever more accurate predictions. Several prevalent approaches to predictive crime modeling are examined in this section: Hot Spot Analysis, Leading Indicators, Polygon Grid/Raster GIS Methods, and Repeat Victimization. Each of these methods (and two additional methods not discussed here) are evaluated in Groff and La Vigne (2002). A number of software manufacturers have developed programs for predictive crime modeling that utilize one or more of the methods discussed here.

\subsubsection{Hot Spot Analysis}

Hot spot analysis is one of the most widely utilized approaches to crime forecasting. This method assumes that hot spots generated from crimes that have already occurred mirror the locations of hot spots in the future. This method is easy to understand and interpret, but requires close attention to the actual predictability of the hot spots to determine the extent to which past occurrences should be used to generate the hot spots. For example, a 1995 study by Spelman (as cited by Groff \& La Vigne, 2002) found that hot spots generated from incidents over a longer period of time had more predictive capability than hot spots generated from only one month of incident data. He found that hot spots generated over one year of incident data accurately predict the locations of future incidents at the 90 percent accuracy level. This finding suggests that hot spots, though not always present, tend to occur in the same locations over longer periods of time. Hot spot analysis is limited in that it is unable to explain why the incidents occur in certain locations, and it is based on the assumption that what was true in the past will be true in the future (Groff \& La Vigne, 2002). 


\subsubsection{Leading Indicators}

The leading indicators method operates on the premise that there are certain precursors that can indicate where a crime is likely to occur. When a precursor occurs or is present (the independent variable) at a certain location, that location becomes more at risk of a certain type of crime (the dependent variable) occurring in the near future. Repeat victimization is a similar concept, which uses actual crime occurrence as a precursor to the same type of crime occurring at the same location in the near future. Leading indicators can be a complicated method to use because of the work involved in identifying the appropriate leading indicators for different crime types. Leading indicators also require that the end user have knowledge of statistics in order to determine which indicators have a significant impact on the dependent variable (Groff \& La Vigne, 2002).

\subsubsection{Polygon Grid/ Raster GIS Methods}

Polygon grid and raster GIS methods use those representations of factors found to have an effect on the occurrence of a certain type of crime. The factors are converted to rasters and combined using map algebra to produce an overall risk surface for the type of crime being studied. This method also requires statistics knowledge to determine the correct combination of factors, and knowledge of model building (Groff \& La Vigne, 2002). The risk terrain modeling method used for this project is a good example of a polygon grid/ raster GIS method.

\subsubsection{Repeat Victimization}

Repeat victimization is the idea that either an individual crime victim or location where a crime has occurred is more likely to be the victim or location of subsequent incident within a few months of the original victimization. While the accuracy of the repeat victimization method has been found to vary depending on the type of crime being studied, repeat victimization has been found to be particularly accurate when applied to burglaries. Two separate studies-Bennett (1996) and Townsley et al. (2000) (as cited by Groff \& La Vigne, 2002)-found that one third of burglaries within hot spots are repeat burglaries. In a 2001 study by Morgan (as cited by Groff \& La Vigne, 2002) found that residences close to repeat victims are also likely to be victimized. Morgan termed these as "near-repeats". A limitation of repeat victimization is that it does not examine what factors influence the locations of the victimizations (Groff \& La Vigne, 2002).

\subsection{Risk Terrain Modeling}

Caplan and Kennedy (2010) developed risk terrain modeling (RTM) at the Rutgers University School of Criminal Justice as a way to examine and ultimately model the social and physical context in which crime occurs. RTM represents the likelihood or opportunity for crime to occur as a continuous surface over the study area. This surface is an aggregate of any number of operationalized risk factors, which are spatial indicators found to correlate to the occurrence of a particular type of crime. Caplan and Kennedy authored the manual for use by crime GIS analysts in integrating the method into their 
own organizations' analytical process. The Risk Terrain Modeling Compendium (Caplan \& Kennedy, 2011) presents potential risk factors for a number of different crimes and further examines the potential applications of RTM. In the following sections, the procedure for RTM are briefly outlined, and an example of an application of Risk Terrain Modeling to residential burglaries is described.

\subsubsection{Procedure}

The RTM Manual provides a detailed description of the RTM method in Chapter 5 (Caplan \& Kennedy, 2010). The data collection and manipulation portion of the method is the most time consuming part of the process, with objectives related to the study area and risk factor selection. Actual implementation of the mathematical model is brief, consisting of only one step. Each of the ten steps and general descriptions are outlined in Table 2-1.

\section{Table 2-1: Risk Terrain Modeling Steps}

\begin{tabular}{|c|c|}
\hline Step & Description \\
\hline Step 1: Select crime type, & $\begin{array}{l}\text { Choose the type of crime that will be } \\
\text { studied. }\end{array}$ \\
\hline Step 2: Choose a study area. & $\begin{array}{l}\text { The study area for RTM can be any size, } \\
\text { but it is important to ensure that the data } \\
\text { are available for the extent chosen and that } \\
\text { the data are detailed enough to produce a } \\
\text { meaningful representation of the potential } \\
\text { risk factors. }\end{array}$ \\
\hline Step 3: Choose a time period. & $\begin{array}{l}\text { The time period that the RTM will } \\
\text { represent depends on the intended purpose } \\
\text { of the final model. If the time period of } \\
\text { interest is a single month, utilizing data } \\
\text { from that month of the previous year is } \\
\text { much more representative than data from } \\
\text { every month of the previous year. }\end{array}$ \\
\hline Step 4: Create a basemap. & $\begin{array}{l}\text { The minimum base map data needed is a } \\
\text { polygon of the area of interest. Other base } \\
\text { map data may be included for aesthetic and } \\
\text { orientation purposes. }\end{array}$ \\
\hline Step 5: Identify risk factors. & $\begin{array}{l}\text { Compile an as comprehensive as possible } \\
\text { list using personal knowledge, empirical } \\
\text { analysis, and literature review. }\end{array}$ \\
\hline
\end{tabular}




\begin{tabular}{|l|l|}
\hline \multicolumn{1}{|c|}{ Step } & \multicolumn{1}{c|}{ Description } \\
\hline $\begin{array}{l}\text { Step 6: Choose risk factors to include in } \\
\text { final model. }\end{array}$ & $\begin{array}{l}\text { Here the comprehensive list of potential } \\
\text { risk factors is reduced based on relevance } \\
\text { to the study at hand and availability of } \\
\text { quality data to represent the factor. More } \\
\text { risk factors do not necessarily produce a } \\
\text { better model. }\end{array}$ \\
\hline $\begin{array}{l}\text { Step 7: Develop spatial representation of } \\
\text { risk factors. }\end{array}$ & $\begin{array}{l}\text { Each risk factor is converted to raster } \\
\text { format in a way that "reasonably and } \\
\text { meaningfully represents the influence of } \\
\text { the risk factor" (Caplan \& Kennedy, 2010, } \\
\text { p. 86). The cell values for each raster are } \\
\text { standardized according to a common index. }\end{array}$ \\
\hline Step 8: Weight risk map layers. & $\begin{array}{l}\text { If the assigned values according to the } \\
\text { common index do not sufficiently serve as } \\
\text { the weight for each risk map layer, logical } \\
\text { regression analysis may be used to } \\
\text { determine the appropriate weights. }\end{array}$ \\
\hline Step 9: Combine risk layers. & $\begin{array}{l}\text { Compilation of the risk map layers is } \\
\text { accomplished using the raster calculator } \\
\text { tool. }\end{array}$ \\
\hline Step 10: Finalize risk terrain output. & $\begin{array}{l}\text { The final composite map is symbolized to } \\
\text { effectively communicate the overall risk } \\
\text { findings. Statistical testing may be done to } \\
\text { determine if any statistically significant } \\
\text { clusters exist. }\end{array}$ \\
\hline
\end{tabular}

Two custom toolsets available online may be used or referred to for RTM implementation. These toolsets were Hawthe's Analysis Tools for ArcGIS (spatialecology.com/htools) and the RTM Toolbox for ArcGIS10 (http://www.rutgerscps.org/rtm/).

\subsubsection{Case Study}

The relative simplicity of the RTM concept, as well as easy access to the RTM manual (available for free download online from Rutgers, The State University of New Jersey) which guides the user through the process in great detail, has resulted in wide adoption of the method by various police departments. Unfortunately, peer-reviewed studies of RTM outside of the Rutgers community are rare, presumably due to the intended use of RTM as a tactical and strategic planning tool for police departments outside the academic arena. 
Included in the Compendium (Caplan \& Kennedy, 2011), however, is a case study by William Moreto applicable to this project on the application of RTM to residential burglaries in Newark, New Jersey. In the case study, Moreto seeks to produce a six-month model utilizing data from the same six months of the previous year, and four risk factors: at-risk housing complexes, pawn shops, bus stops, and guardian infrastructures (the last is a mitigating risk factor) (Caplan \& Kennedy, 2011). A binary logistic regression analysis was used to test the validity of the composite risk terrain map against data from the corresponding six-month period of the second year. The analysis found that for every unit increase in the RTM actual risk of burglary occurring in that location also increased by 15 percent.

\subsection{Spatial Influences of Burglaries}

Burglary is defined as "the illegal and unlawful entry into a home or structure to commit a felony or theft" (Caplan \& Kennedy, 2011). Burglaries can be more narrowly categorized as residential burglaries and commercial burglaries. Types of burglaries can be broken down further to residential or commercial. For example, residential burglary is further categorized by the type of structure and design of the residence, and by occupancy type (Caplan \& Kennedy, 2011). Aggravating and mitigating risk factors presented in the RTM Compendium for residential burglary are specific to those of urban residential burglary. The City of Redlands is decidedly suburban, however the factors presented in the case study on residential burglary may be examined for integration in a suburban model of burglary. In this section, the guidance provided in the Residential Burglary Section of the Risk Terrain Modeling Compendium are examined, along with the works of several other researchers who have found certain factors to increase risk of burglary.

\subsubsection{Proximity to High Schools}

The effect that the proximity of high schools has on crime rates in the surrounding area is a topic that has been thoroughly researched. Roncek and Faggiani (1985) sought to replicate the findings in a previous 1982 study by Roncek and LoBosco which found that residential areas adjacent to public high schools had more crime than those areas which were more than one block away in 1970s San Diego. In Roncek and Faggiani's study, they attempted to determine if these findings would hold true for the more traditional city of Cleveland, Ohio, for the same study year.

As had been done in the previous study, city blocks were used as the unit of analysis. A number of crime types were chosen as dependent variables, proximity to high schools was chosen as the primary independent variable, and a number of control variables related to neighborhood social and demographic composition, as well as residential environment were selected for use in the regression model (Roncek \& Faggiani, 1985). A preliminary t-test found that blocks with or adjacent to public high schools experienced statistically significant higher levels of burglaries at the $p=0.002$ significance level. Next, the researchers used multiple regression to examine the association across all residential blocks, and found that the control variables do not distort the effect of proximity to high schools on crime levels in the adjacent area. Finally, it was found that adjacency to public high schools had a statistically significant effect on burglaries, as well as all of the other crime types included in the study. 


\subsubsection{Accessibility}

Proximity to major thoroughfares or other modes of transportation has been found in a number of studies to have an impact on crime, and specifically residential burglaries. Proximity to major thoroughfares is a factor that was studied by Groff and La Vigne (2001) to create an opportunity map of residential burglaries. The authors cited three previous studies as justification for including proximity to major thoroughfares as a factor in their study: Wright and Decker (1994) found that there is increased likelihood that a burglar is familiar with a residence along a well-traveled road due to their continually scanning for potential targets (as cited by Groff \& La Vigne, 2002). Buck et al. (1993) and Luedke and Associates (1970) found that burglars extend their search for potential targets two to three blocks from roads, entertainment venues, and employment centers (as cited by Groff \& La Vigne, 2001). The study did not examine the precise relationship between proximity to major thoroughfares and residential burglary, but used the factor along with a number of others to create an opportunity map of residential burglaries.

In addition, Beavon, Brantingham, and Brantingham (1994) analyzed spatial patterns of property crime through the use of two manufactured measures of accessibility: "TURNS", and "FLOW". The independent "TURNS" variable measured the accessibility of a particular street segment by counting the number of adjacent streets that can be used to access the street segment in question. The independent "FLOW" variable was directly related to road type: highway, major road, minor road, etc. The authors found that while both variables are related to property crime, it is important to note that all property crime types were considered in the study. Therefore, higher rates of crime along more accessible roads with higher flow are to be expected, because it is at these locations where hotels, bars, and other types of establishments that may experience higher rates of crime due to other factors are typically located.

\subsubsection{Lighting and Surrounding Area}

Apart from high schools, major thoroughfares, and highways, a number of factors relating to the surrounding physical environment must be considered for their effect on burglary locations. Lighting, proximity to vacant lots and wooded areas, and proximity to pawn shops are a few such independent variables that have been linked to residential burglaries through research.

Proximity to vacant lots and wooded areas was a factor utilized in Groff and $\mathrm{La}$ Vigne's 2001 residential burglary opportunity study. A study conducted in 1993 by Buck, Hakim, and Rengert (as cited in Groff \& La Vigne, 2001) found that culs de sac surrounded by woods were more likely to be burglarized, and that homes adjacent to vacant lots have an increased risk of being burglarized due to reduced chance that a neighbor might observe the burglary in progress.

Proximity to pawn shops is listed in the Risk Terrain Modeling Compendium as a factor contributing to urban residential burglaries. According to the compendium, this is particularly a factor in impoverished areas, due to the need of offenders to quickly liquidate burgled items (Caplan \& Kennedy, 2011). Proximity to pawn shops was one of the factors utilized in the RTM case study described in the previous section.

Street lighting was used as a factor in Groff and La Vigne (2001). Through their preliminary research, they found that improvements in street lighting are associated with 
crime reduction for all types of crime. A study undertaken by the Crime Prevention Unit in London, England, however, did not find such an association. Following a campaign invested in improving street lighting, their study found that in areas where street lights were added, no evidence was found to support their hypothesis that an improvement in street lighting leads to a reduction in crime (Atkins, Husain, \& Storey, 1991).

\subsubsection{Social and Economic Indicators}

Two additional factors that may influence the locations of residential burglaries are income and high residential mobility. The Compendium lists both of these (in addition to high levels of ethnic homogeneity) as measures of social disorganization that have been found to be correlated with urban residential burglary (Caplan \& Kennedy, 2011). Groff and La Vigne (2001) includes similar variables, such as housing tenure, which measures whether a housing unit is renter occupied or owner occupied. The tenure of dwelling occupants may have an effect on the sense of guardianship within the neighborhood, thus either encouraging or discouraging potential burglars.

The Compendium also adds that socially disadvantaged neighborhoods may have a higher number of arrestees living nearby, thereby increasing burglary risk (Caplan \& Kennedy, 2011). Therefore, proximity to arrestees may also be an important factor to consider. The study narrowed this down to proximity to likely offenders, using only the residence addresses of arrested burglars to indicate an increased risk (Groff \& La Vigne, 2001).

\subsubsection{Temporal Variation}

Temporal variation is another possible component that can be utilized in predicting where (or in this case, when) times are more likely to occur. For example, if assault locations have been found to correlate to the locations of bars, perhaps this correlation is less so during the daytime before the bar opens, increasing in risk as the evening goes on, and peaking when the bar closes and the remaining patrons are expelled from the bar into the surrounding areas. Gorr, Olligschlaeger, and Thompson (2003) found that at least 30 incidents per month are needed in order for forecast errors to be acceptable. For a city as small as Redlands, this is an extremely high number when accounting for only one crime type. Corcoran, Wilson, and Ware (2003) were able to identify high crime cluster areas using a geographical crime incidence-scanning algorithm where a sufficient amount of incidents had occurred in order to produce an accurate model. In order for the forecast error to be acceptable, however, 25 to 35 incidents per unit of time analysis are needed.

The aim of this project was not to produce a predictive model based on temporal data alone; temporal variations will be included to account for known time / crime correlations. Felson and Poulsen (2003) suggest that when studying the variations of crime over the course of a day, the way to measure a day from a criminological standpoint is from 5am to 4:59am. Predicting risk of residential burglaries by time of day is difficult, however, because the incident is often discovered only when a resident returns home, leaving the specific incident occurrence time a mystery (Felson \& Poulsen, 2003).

While the specific time of past burglaries may not be available, the timeframe in which they have occurred yields important information for predictive modeling. Most 
residential burglaries occur when the home is unoccupied. For most, this is during the work day between 8am and 6pm Monday through Friday (Caplan \& Kennedy, 2011). Seasonal variations may also play a role in predicting when residential burglaries are most likely to occur. "Hot products" (such as popular electronics) are most likely to be in homes during the winter holiday season, thereby increasing risk of burglary, while increased guardianship by children home from school in the summer time may decrease risk of burglary (Caplan \& Kennedy, 2011). Time spent away from the home while on vacation may also be correlated to residential burglaries (Caplan \& Kennedy, 2011).

\subsection{Summary}

A number of different methods exist to predictively model crime. A few of these methods were discussed in this section, as was the Risk Terrain Modeling method which will be used for this project per the request of the client. A number of factors that have been found through research to be correlated to residential burglaries were examined. These factors, and others, will be considered for use in the project. The following section discusses the system analysis and design process. 


\section{Chapter 3 - Systems Analysis and Design}

This chapter focuses on analyzing the problem that this project seeks to solve for the client by breaking it down into a series of requirements. By examining the problem and the corresponding requirements necessary to solve the problem, a basic system design was developed. In Section 3.1, the problem is reviewed, followed by a breakdown of requirements necessary to solve the problem in Section 3.2. A general system design is presented in Section 3.3 and the preliminary project plan is introduced.

\subsection{Problem Statement}

Much of the police patrolling in the City of Redlands is based on legacy patrol routes and individual officers' knowledge of the community. Because crime is dynamic over time, it can be difficult to keep patrols current with ongoing trends in the locations of crimes. Traditional threat models depicting crime as "hot spots" only show the spatial distribution of past crime incidents without forecasting the future crime distribution in space.

Therefore, the Police Department of Redlands sought a new crime model that can better predict crime-prone areas based on the past crime distribution and other relevant factors.

\subsection{Requirements Analysis}

This section outlines the functional and non-functional requirements for this project. Functional requirements are what the tool or software under development must be able to do for the user. Non-functional requirements refer to particular qualities that the tool or output must possess. The primary functional requirement was to develop the Risk Terrain Modeling tool that can help the police department better predict future crime-prone areas. The tool must be an ArcGIS tool implementation of the Risk Terrain Modeling Method. The primary non-functional requirement of the project was to develop the tool for use in Esri ArcMap as the client already regularly uses Esri ArcGIS 10 products. Table 3-1 outlines the functional and non-functional requirements of this project.

Table 3-1: Functional and Non-Functional Requirements

\begin{tabular}{|l|l|}
\hline \multicolumn{1}{|c|}{ Functional Requirements } & \multicolumn{1}{c|}{ Non-Functional Requirements } \\
\hline Risk Terrain Modeling Tool & Intuitive interface \\
\hline Dynamically query city databases & Fast risk surface generation \\
\hline Specify date ranges for queries & Functions using ArcGIS 10 \\
\hline & Validated sample output \\
\cline { 2 - 2 } & Provide tool documentation \\
\hline
\end{tabular}

The following sections present the functional and non-functional requirements in more detail. 


\subsubsection{Functional Requirements}

Functional requirements are what the tool must be able to do, or functions that the tool must possess. This project sought to fulfill the fundamental functional requirement of the client: a Risk Terrain Modeling Tool that generates a predictive crime map of a specific crime type for the City of Redlands. The Risk Terrain Modeling tool should allow the user to generate a risk terrain model based on the most current information by opening the RTM tool, selecting the desired risk factors, and assigning each factor a weight (if necessary).

Additionally, the tool must have the ability to query specific date ranges by which the dynamic city databases are queried. This allows the user more control of the risk factor generated from the dynamic city databases.

\subsubsection{Non-Functional Requirements}

Non-functional requirements may be broken down into technical, operational, and transitional. Technical requirements refer to operating system considerations, while operational requirements refer to the design of the tool. Transitional requirements are items that are necessary for delivery to the user.

The primary operational non-functional requirement was that the RTM tool have an intuitive user interface. The primary users for the tools are non-GIS trained law enforcement professionals who are not familiar with Esri software. A GIS specialist (the client) is on-site to integrate the software into the daily workflow and keep the tool updated and relevant.

The primary technical non-functional requirement of the Risk Terrain modeling tool was that the tool function in the ArcGIS Desktop 10 environment. Additionally, the tool was developed using the Python scripting language. The user must have Python 2.7 and the Spatial Analyst extension for ArcGIS.

Another technical non-functional requirement dictated that the model output be validated through a case study. The risk terrain modeling tool and the associated work flow were demonstrated in this project using residential burglary. Potential factors influencing residential burglary were prepared for use in the model, validated using statistical significance testing, and turned over to the client for future model building. If in the future additional factors are identified, the client is familiar with the risk terrain modeling method and will be able to prepare that dataset and add it to factor options that reside in a database delivered to the client.

The transitional requirement of this project consisted of delivery of the completed tool to the client. Necessary documentation on tool functionality and operation, as well as documentation of the case study were provided to the client. This documentation will aid the client in generating new risk surfaces for residential burglaries, and in developing risk surfaces for additional crime types.

\subsection{System Design}

A system design was generated from the functional and non-functional requirements. Figure 3-1 outlines the major components of the system that were developed in this project. This section outlines these major components. 


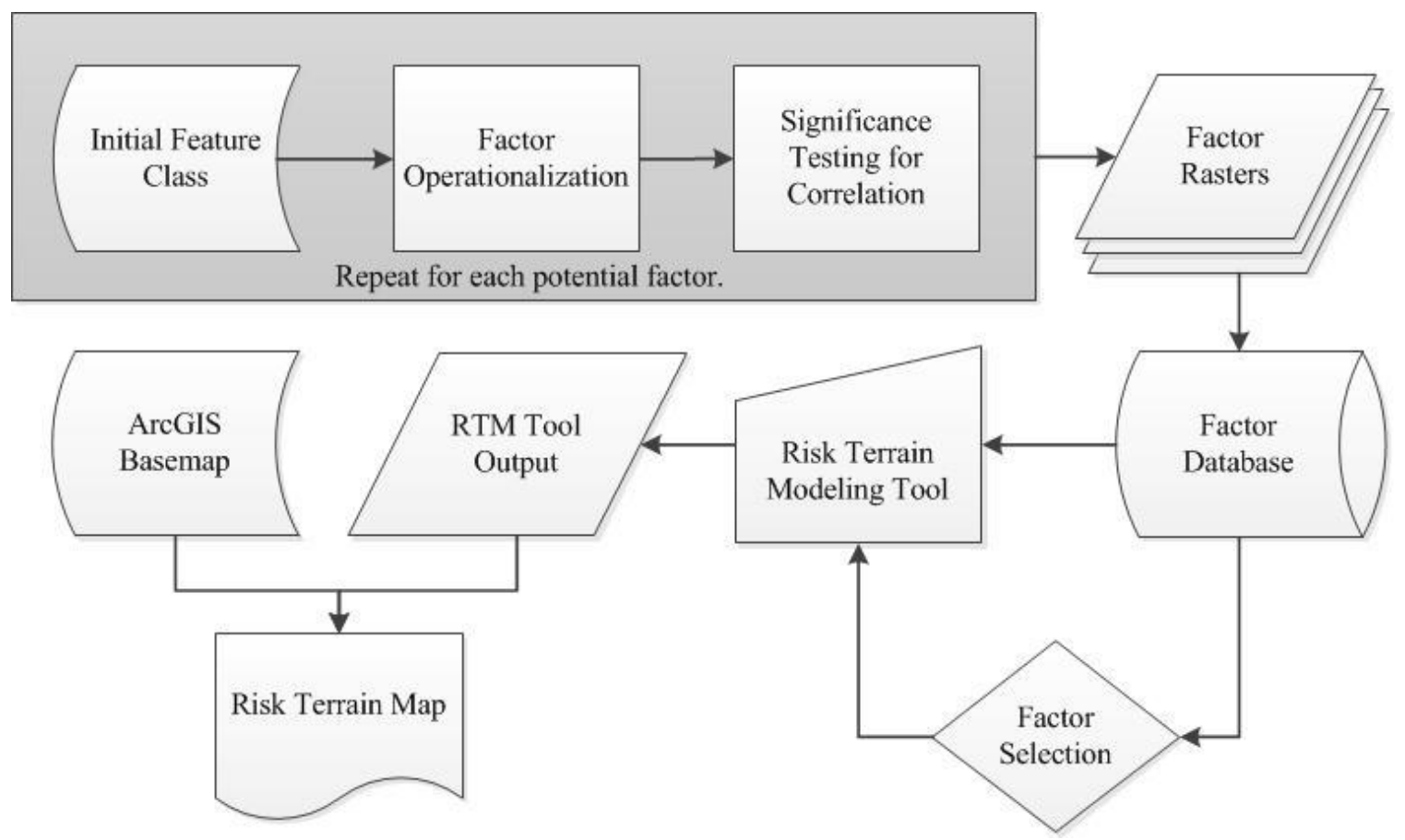

Figure 3-1: System Design

In order to execute the Risk Terrain Modeling tool, a number of factors found previously to be correlated with residential burglary were chosen. These factors, such as proximity to pawn shops, needed to be operationalized from point or polygon data in a way that accurately reflects the spatial influence (or areal effect) of the factor. Once operationalized, the each factor was tested for statistically significant correlation with residential burglaries. Those factors passing the significance test were each converted to raster and loaded into the factor database. The factor database is the location from which inputs to the Risk Terrain Modeling Tool are chosen. In the RTM Tool interface, factors are chosen, and the tool is run. When complete, the tool produces an output, or a risk surface. This surface automatically displays in ArcMap on top of an online ArcGIS basemap of the city for reference.

\subsection{Project Plan}

The original project plan includes seven major tasks, shown in Figure 3-2. 


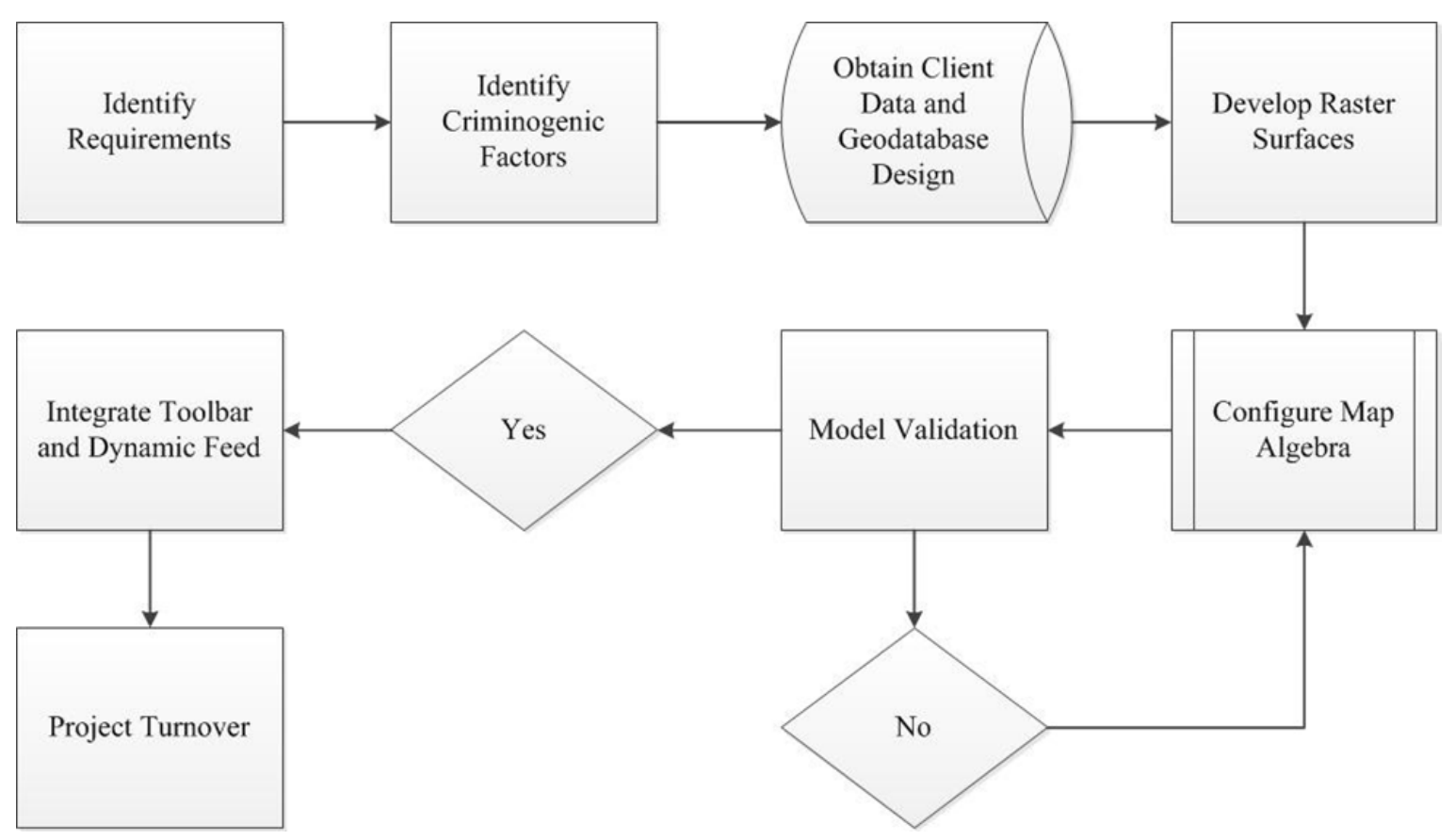

Figure 3-2: Project Plan

Task 1: Identify Requirements: The first step in this project was to meet with the client and identify specific needs and overall goals for the project.

Task 2: Identify Criminogenic Factors: During this stage literature was reviewed in order to identify factors that have been shown to have an association with crime and crime risk. Final determination of which factors to include was decided by the client.

Task 3: Obtain Client Data and Geodatabase Design: The client provided almost all of the necessary data. Once these data were identified and acquired, they were organized into a temporary geodatabase. The final geodatabase containing finalized risk factor surfaces was created after Task 4.

Task 4: Develop Raster Surfaces: Factors identified in Task 2 were operationalized, tested, and converted to a raster format. These rasters were combined using the Risk Terrain Modeling Tool to create the risk surface. Originally, risk surfaces were supposed to be developed for five separate crime types. These were reduced to one case study on residential burglaries to demonstrate and validate the RTM tool function.

Task 5: Model Validation: During this phase of the project the output raster surface created in Task 4 was evaluated against residential burglaries that occurred during a test period using binary logistic regression. The goal of this step was to confirm that residential burglaries within the test period are occurring in places that are shown by the model to have an increased risk of that particular type of crime or incident.

Task 6: Integrate Toolbar and Dynamic Feed: The final step before project completion was to implement a simple toolbar that will allow officers to easily visualize the predicted risk scores for different areas. This was to be achieved by developing a tool that will automatically retrieve the latest data from the dynamic city databases and recalculating the model on demand for selected areas. Instead, this dynamic function was incorporated into the Risk Terrain Modeling Tool. The toolbar was deemed unnecessary for the project. 
Task 7: Project Turnover: For this final step, the project was demonstrated to the client. The tool was transferred to the client so that they may utilize it to generate their own models.

Several changes were made to the project plan. Rather than produce multiple crime surfaces, the decision was made to produce the tool and thoroughly analyze one crime type-residential burglaries-as a case study to demonstrate the tool's functionality and test tool reliability. The toolbar in Step 7 was also eliminated, as it was no longer necessary with only one crime type developed and dynamic querying implemented within the tool.

\subsection{Summary}

Functional and non-functional requirements of the tool were assessed in the requirements analysis. The system design presented shows the general flow of the system from conceptual risk factors to output risk surface map. The plan for completing the project outlines the general steps that were required to complete this project. In the following chapter, the data and requirements are examined in order to produce a conceptual model and logical implementation for this project in a GIS. 



\section{Chapter 4 - Database Design}

The conceptual model and logical model for the Risk Terrain Modeling (RTM) tool are presented in this chapter. The conceptual model represents the risk terrain modeling process. The logical model is presented as the implementation of the conceptual model using a case study of residential burglaries. Data sources and collection methods are also discussed.

\subsection{Conceptual Data Model}

The major entities involved in the RTM tool, as well as their interrelationships, were identified in the conceptual data model, displayed in Figure 4-1.

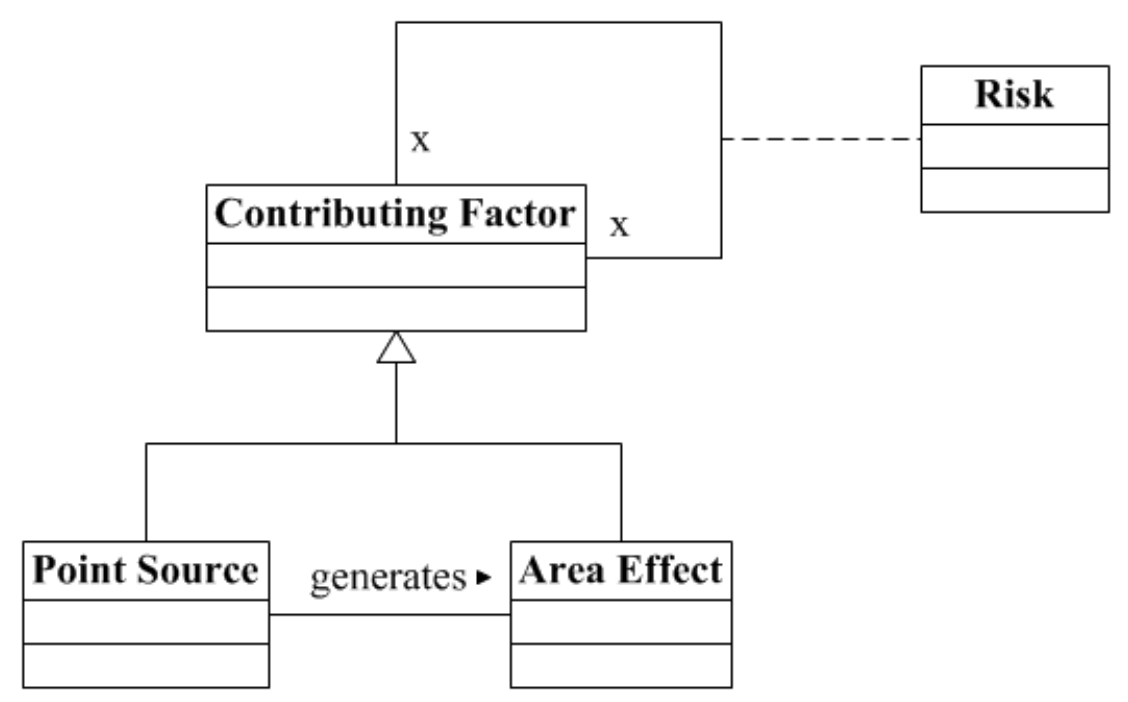

Figure 4-1: Conceptual Data Model

Four main objects were used to develop the RTM tool: point sources, area effects, contributing factors, and the risk surface. In order to implement the RTM the conceptualized risk factors had to be operationalized. An example of a conceptual risk factor is "Residences within one mile of pawn shops are at increased risk of being burglarized because close proximity to pawn shops allows a burglar to quickly liquidate burgled items". This conceptual risk factor had to be given a spatial representation for use in the model. Point sources were the original data from which each risk factor were operationalized. In the previous example, the locations of pawn shops in Redlands are point sources. The point itself, however, does not represent increased risk to homes nearby. From the point source, an area effect must be generated. In this example, the pawn shops are buffered out to one mile along the road network. This is the area effect. Together, the point source and their area effects form the contributing factor for use in the risk terrain model. There may be any number of contributing factors generated from their respective point sources and area effects. The desired number of contributing factors are 
compiled and produces a risk surface. The risk terrain surface shows the risk, or likelihood of the studied crime type occurring, throughout the study area.

\subsection{Logical Data Model}

According to the literature, different types of crime may have different sets of contributing factors. Although the RTM tool was set up for use with any crime type that the user chooses, residential burglary was chosen as the crime type for the implementation. Thus, the logical model for this project is represented using residential burglary as the crime type of interest.

A number of factors were considered as potential input factors for residential burglaries. These potential factors were identified using several different methods. Some factors were chosen after being identified during the literature review process, including from the Risk Terrain Modeling Compendium (Caplan \& Kennedy, 2011). The remaining potential factors were chosen based on the client team's collective personal and professional knowledge of crime patterns in the City of Redlands.

Table 4-1: Potential Factors List for Residential Burglary

\begin{tabular}{|l|}
\hline \multicolumn{1}{|c|}{ Residential Burglaries } \\
\hline Residential land use \\
\hline Access to freeway \\
\hline Lighting \\
\hline Cover provided by vegetation \\
\hline Proximity to schools \\
\hline Areas adjacent to wooded areas or vacant lots \\
\hline Proximity to bus stations \\
\hline Proximity to arrestees \\
\hline Income \\
\hline Proximity to pawn shops \\
\hline Proximity to thoroughfares \\
\hline Population Density \\
\hline Household Density \\
\hline
\end{tabular}

All of these potential factors were tested using the Chi-square test on crosstab data, and the ones that significantly correlated with residential burglary were considered for inclusion in the final model, and loaded into the database. Figure 4-2 shows the logical data model of the RTM tool. 

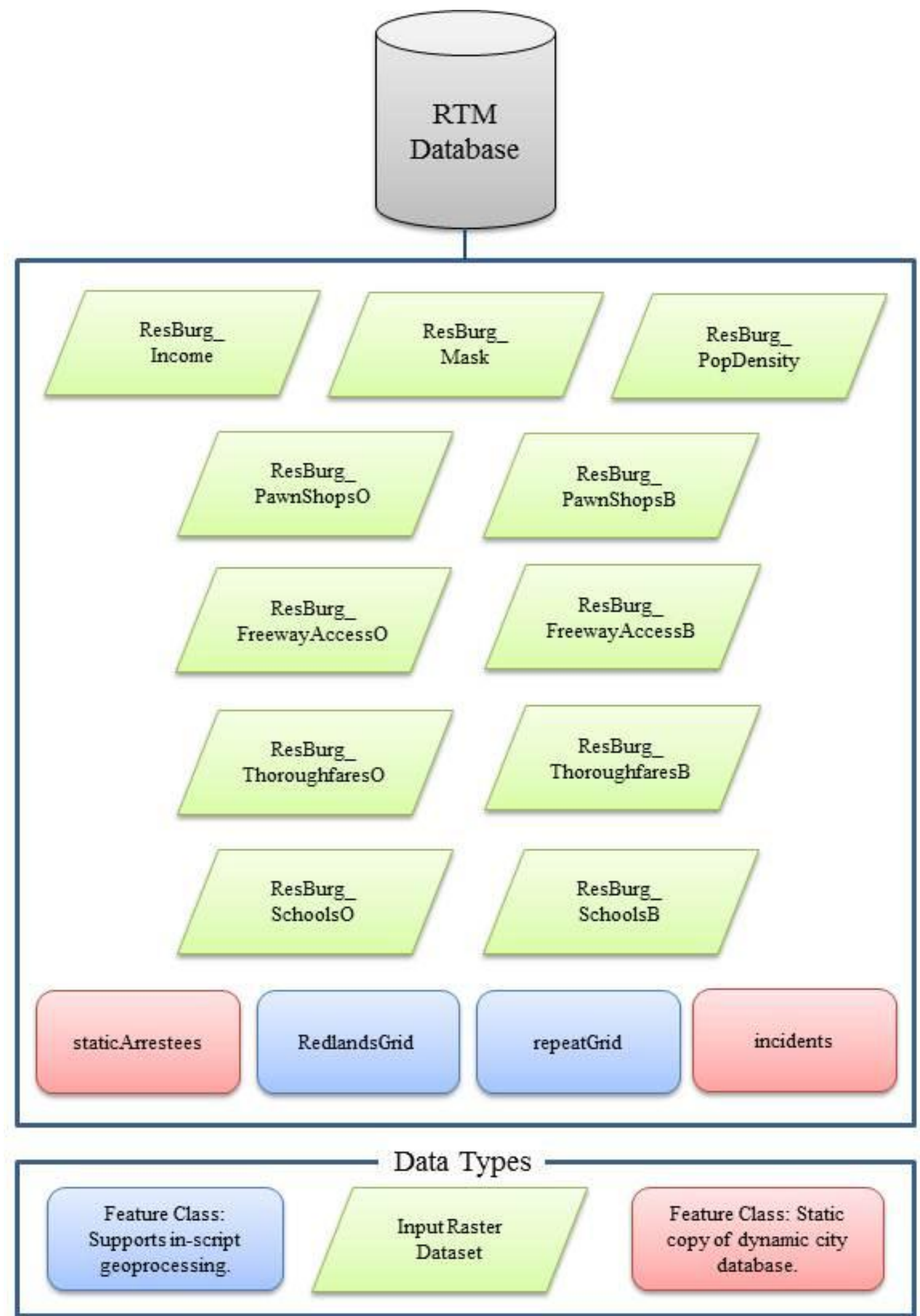

Figure 4-2: Logical Data Model 
Both raster layers and feature classes were included in the final geodatabase. The raster layers included the three operationalizations of the following factors: access to freeways factor (ResBurg_FreewayAccessO and ResBurg_FreewayAccessB); proximity to major thoroughfares (ResBurg_ThoroughfaresO and ResBurg_ThoroughfaresB); proximity to schools (ResBurg_SchoolsO and ResBurg_SchoolsB); proximity to pawn shops (ResBurg_PawnShopsO and ResBurg_PawnShopsB). The remaining factor rasters included income (ResBurg_Income), population density (ResBurg_PopDensity), and residential land use (ResBurg_Filter). All of these raster layers represent the factors that significantly affect residential burglary in Redlands. The proximity to past arrestees (Staticarrests) is another important factor, which is represented by a point feature class in the database. This feature class, which is a static image of a dynamic city of Redlands database, is queried from within the tool in order to produce the actual risk factor surface. Finally, a static image of the Redlands incident database (incidents) is included in the RTM database to produce a proximity to recent residential burglaries (near-repeats) factor. Two 100-foot by 100-foot vector grids covering the Redlands study area (RedlandsGrid and RepeatGrid) were also included in the database to support in-script creation of the proximity to arrestees and near-repeats factors.

\subsection{Data Sources}

The client provided most of the data for this project. However, it is notable that almost all of the data provided by the client were severely lacking in metadata. For example, data dictionaries explaining attribute names and coding/abbreviations in each attribute were not available for all files provided by the client. In order to query the residential burglary incidents from the crime data, the client was contacted for input.

Several prospective factors utilized in the case study were obtained from sources other than the client. These datasets included pawn shop locations, bus stop locations, and income data. No datasets containing the locations of pawn shops were accessible for this project, so the local pawn shops were looked up and geocoded to the Redlands streets. The locations of bus stops were also not available. A bus route dataset was located through the San Bernardino Associated Governments webpage (sanbag.ca.gov) as a potential substitute for bus stop data. It was determined that bus route data would probably not have the same spatial correlation to crime as more specific bus stop locations, so this dataset was excluded from the list of potential factors for the case study.

\subsection{Data Scrubbing and Loading}

Table 5-1 lists all the risk factors considered for this project. However, data on the cover provided by vegetation and proximity to bus stations were not available and therefore removed from the potential factors list for the time being. 
Table 4-2: Potential Factors

\begin{tabular}{|l|c|}
\hline \multicolumn{1}{|c|}{ Potential Factor } & Data Available? \\
\hline Residential land use & \\
\hline Access to freeway & \\
\hline Lighting & \\
\hline Cover provided by vegetation & \\
\hline Proximity to schools & \\
\hline Areas adjacent to wooded areas or vacant lots & \\
\hline Proximity to bus stations & \\
\hline Proximity to arrestees & \\
\hline Income & \\
\hline Proximity to pawn shops & \\
\hline Proximity to thoroughfares & \\
\hline Population Density & \\
\hline Household Density & \\
\hline
\end{tabular}

Table 5-2 describes the data preparation process for each of the remaining factors. In this stage, data for each factor are prepared for implementation of their respective areal effects, which will be further discussed in Chapter 5 .

\section{Table 4-3: Data Preparation}

\begin{tabular}{|c|c|}
\hline $\begin{array}{l}\text { Potential } \\
\text { Factor }\end{array}$ & Data Preparation \\
\hline $\begin{array}{l}\text { Residential } \\
\text { Land Use }\end{array}$ & $\begin{array}{l}\text { The residential land use factor was operationalized from the } \\
\text { SCAGLandUse } 2005 \text { feature class. An SQL query was used to select } \\
\text { residential land use types. The selected parcels were exported and } \\
\text { clipped to the Redlands area of interest. }\end{array}$ \\
\hline $\begin{array}{l}\text { Access to } \\
\text { Freeeway }\end{array}$ & $\begin{array}{l}\text { To operationalize access to freeway, a network dataset was created in } \\
\text { ArcGIS using the streets feature class provided by the client, and a } \\
\text { distance cost was added to the network. A HighwayExits feature class } \\
\text { representing locations where the highway may be exited was manually } \\
\text { digitized for use with the network dataset. }\end{array}$ \\
\hline Lighting & $\begin{array}{l}\text { The client-provided rSCELights and rLights feature classes } \\
\text { representing the locations of lights within Redlands were merged. }\end{array}$ \\
\hline $\begin{array}{l}\text { Proximity to } \\
\text { Schools }\end{array}$ & $\begin{array}{l}\text { Data for the proximity to schools factor was prepared by creating two } \\
\text { separate feature classes for testing: one includes middle and high } \\
\text { schools, and the other includes middle schools, high schools, and } \\
\text { colleges. These were manually selected from the original file attribute } \\
\text { table based on the name of the school. }\end{array}$ \\
\hline
\end{tabular}




\begin{tabular}{|c|c|}
\hline $\begin{array}{l}\text { Potential } \\
\text { Factor }\end{array}$ & Data Preparation \\
\hline $\begin{array}{l}\text { Areas Adjacent } \\
\text { to Wooded } \\
\text { Areas or } \\
\text { Vacant Lots }\end{array}$ & $\begin{array}{l}\text { Data for this factor was obtained from two sources: the Vacant and } \\
\text { CityGroves feature classes provided by the client. Groves were used as } \\
\text { the Redlands interpretation of wooded areas. The Vacant feature class } \\
\text { was queried for attributes that had "Yes" in the "Vacant" field. The } \\
\text { selection was exported to another feature class (VacantLand) and } \\
\text { subsequently merged with the CityGroves feature class. }\end{array}$ \\
\hline $\begin{array}{l}\text { Proximity to } \\
\text { Past Arrestees }\end{array}$ & $\begin{array}{l}\text { The arrestees shapefile contains points corresponding to the home } \\
\text { addresses of arrestees. A kernel density was applied to create a density } \\
\text { raster with a } 100 \text { foot by } 100 \text { foot cell size. A search radius of } 1,500 \\
\text { unit and areal units of square miles were used. }\end{array}$ \\
\hline Income & $\begin{array}{l}\text { Household median income data from the } 2010 \text { US Census was used to } \\
\text { operationalize this factor. The data is at the census tract level and } \\
\text { processed and joined to the census tract feature class. }\end{array}$ \\
\hline $\begin{array}{l}\text { Proximity to } \\
\text { Pawn Shops }\end{array}$ & $\begin{array}{l}\text { A feature class of pawn shops was created by looking up local pawn } \\
\text { shops, adding their addresses to a table, and geocoding the addresses } \\
\text { to Redlands streets. }\end{array}$ \\
\hline $\begin{array}{l}\text { Proximity to } \\
\text { Throughfares }\end{array}$ & $\begin{array}{l}\text { An incomplete street network containing traffic volume data was used } \\
\text { to identify and select high-traffic streets from the streets feature class } \\
\text { for this factor. Streets with traffic volumes greater than } 8,000 \text { were } \\
\text { selected from the incomplete dataset and streets identical to those in } \\
\text { the streets feature class were selected, in addition to sections of roads } \\
\text { known to be high in volume but missing from the traffic volume } \\
\text { dataset. The selected streets were exported as a new feature class of } \\
\text { only high traffic volume streets. }\end{array}$ \\
\hline $\begin{array}{c}\text { Population } \\
\text { Density }\end{array}$ & $\begin{array}{l}\text { Census block groups released by Esri contained } 2010 \text { population } \\
\text { density per square mile for each block group. }\end{array}$ \\
\hline $\begin{array}{c}\text { Household } \\
\text { Density }\end{array}$ & $\begin{array}{l}\text { Census block groups (2010) released by Esri contained the number of } \\
\text { households per census block group. This data was converted to } \\
\text { household density by dividing the number of households in each block } \\
\text { group by the respective block group area per square mile. }\end{array}$ \\
\hline
\end{tabular}

\subsection{Summary}

In this chapter, the conceptual model for the tool was presented. The logical implementation of the conceptual model was presented for residential burglary. Data sources for the project were discussed, and data that needed to be obtained from sources other than the client were identified. 


\section{Chapter 5 - Implementation}

This chapter details the techniques used to implement the Risk Terrain Modeling (RTM) tool in ArcGIS. First, the operationalization of the risk factors of residential burglary is discussed. The user interface design for the RTM tool is then presented. The primary processes in the Python script behind the tool are explored.

\subsection{Risk Factors' Operationalization}

Each potential factor required careful individual review in order to make the existing data most accurately represent that potential factor. This section briefly outlines the processes of "operationalizing" the risk factors in the forms of point, line, or polygon based feature classes. The conceptual area effect that each factor may have on its surrounding environment with respect to the likelihood of residential burglary occurrence was achieved by rasterizing the corresponding feature class based on the specific criteria.

Figure 5-1 illustrates the general workflow of how the risk factors were prepared for the RTM tool. How each factor was initially operationalized with a vector grid is explained in this section; Factor correction and normalization will be discussed in Section 5.2 and 5.3 respectively.

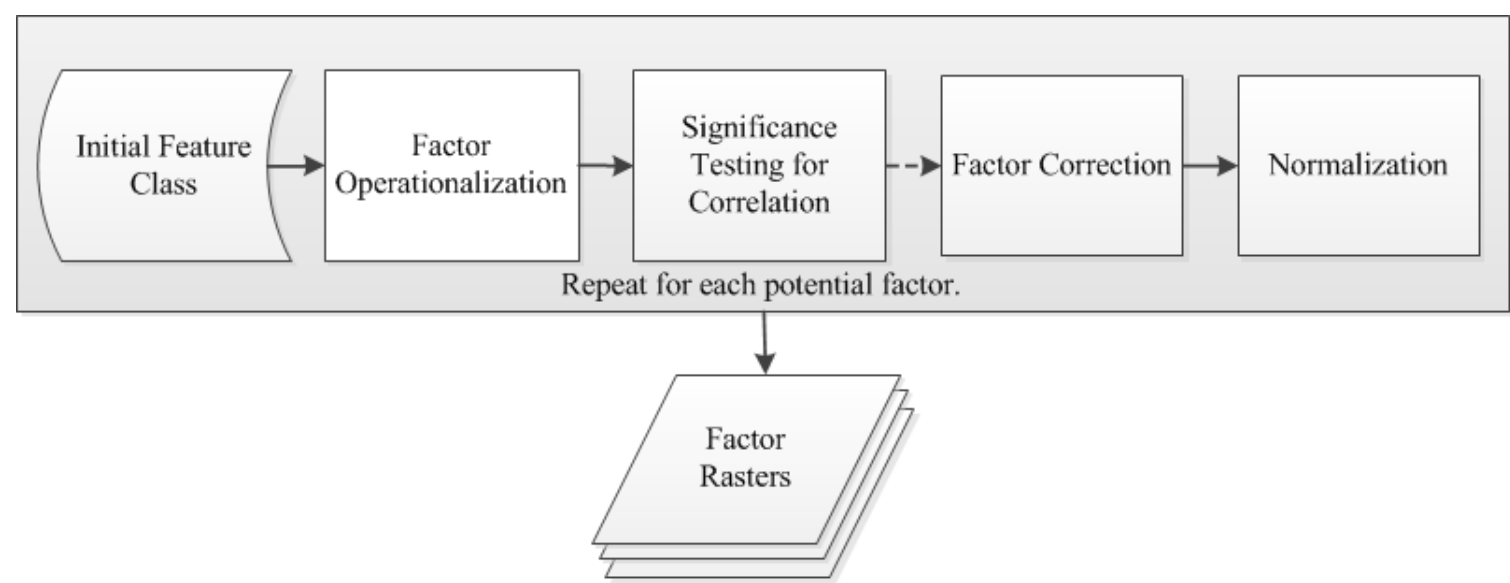

Figure 5-1: Factor Operationalization

Factor operationalization included two major steps. First, the preprocessed feature classes of the risk factors were further processed to represent their area effects on residential burglaries. Various buffers were created for some feature classes, including highway exits, schools, thoroughfares, pawn shops, vacant land, and groves. The buffered areas were then coded based on how the impact of the risk factors on residential burglaries may change with distance (Table 5-1). The codes at this stage were arbitrary, and were adjusted after the correlation test and normalization. For the rest of the feature classes, such as income, population density, household density, proximity to lighting, and proximity to arrestees, they were simply classified into different categories in preparation for the statistical test on correlation (Chapter 6). 
Table 5-1: Areal Effect Implementation

\begin{tabular}{|c|c|c|}
\hline Factor & Ranges & $\begin{array}{l}\text { Coded } \\
\text { Value }\end{array}$ \\
\hline \multirow{2}{*}{ Residential Land Use } & Residential Land Use & 1 \\
\hline & Not Residential Land Use & 0 \\
\hline \multirow{5}{*}{ Access to Freeway } & $0-0.25$ mile & 4 \\
\hline & $0.25-0.5$ mile & 3 \\
\hline & $0.5-0.75$ mile & 2 \\
\hline & $0.75-1$ mile & 1 \\
\hline & $>1$ mile & 0 \\
\hline \multirow{2}{*}{ Proximity to Lighting } & Cell within 50 feet of street light & 1 \\
\hline & Cells not within 50 feet of street light & 0 \\
\hline \multirow{6}{*}{ Proximity to Schools } & $0-264$ feet & 5 \\
\hline & $264-528$ feet & 4 \\
\hline & $528-792$ feet & 3 \\
\hline & $792-1056$ feet & 2 \\
\hline & $1056-1320$ feet & 1 \\
\hline & $>0.25$ mile & 0 \\
\hline \multirow{6}{*}{$\begin{array}{l}\text { Proximity to Groves } \\
\text { and Vacant Lots }\end{array}$} & $0-264$ feet & 5 \\
\hline & $264-528$ feet & 4 \\
\hline & $528-792$ feet & 3 \\
\hline & $792-1056$ feet & 2 \\
\hline & $1056-1320$ feet & 1 \\
\hline & $>0.25$ mile & 0 \\
\hline \multirow{4}{*}{ Proximity to Arrestees } & $0-480$ arrestees & 0 \\
\hline & $480-1800$ arrestees & 1 \\
\hline & $1800-4800$ arrestees & 2 \\
\hline & $4800-10100$ arrestees & 3 \\
\hline \multirow{3}{*}{ Income } & Less than $\$ 66,815$ & 1 \\
\hline & $\$ 66,815$ to $\$ 105,683$ & 2 \\
\hline & Above $\$ 105,683$ & 3 \\
\hline \multirow{5}{*}{$\begin{array}{c}\text { Proximity to Pawn } \\
\text { Shops }\end{array}$} & $0-0.25$ mile & 4 \\
\hline & $0.25-0.5$ mile & 3 \\
\hline & $0.5-0.75$ mile & 2 \\
\hline & $0.75-1$ mile & 1 \\
\hline & $>1$ mile & 0 \\
\hline \multirow{6}{*}{$\begin{array}{l}\text { Proximity to Major } \\
\text { Thoroughfares }\end{array}$} & $0-132$ feet & 0 \\
\hline & $132-264$ feet & 4 \\
\hline & $264-396$ feet & 3 \\
\hline & $396-528$ feet & 2 \\
\hline & $528-660$ feet & 1 \\
\hline & $>660$ feet & 0 \\
\hline
\end{tabular}




\begin{tabular}{|c|r|c|}
\hline Factor & Ranges & $\begin{array}{c}\text { Coded } \\
\text { Value }\end{array}$ \\
\hline \multirow{3}{*}{ Population Density } & 9 to 1,711 people per square mile & 1 \\
& 1,712 to 4,413 people per square mile & 2 \\
& 4,414 to 8.121 people per square mile & 3 \\
& Greater than 8,122 people per square mile & 4 \\
\hline \multirow{3}{*}{ Household Density } & 3 to 786.9 households per square mile & 1 \\
& 787 to $1,936.9$ households per square mile & 2 \\
& 1,937 to 3,450.9 households per square mile & 3 \\
\hline
\end{tabular}

Once all the feature classes were recoded into categories, they were overlaid with a blank vector grid, which serves as the analysis unit in risk terrain modeling. All factors were tested, rasterized, and overlaid on the vector grid. The blank vector grid (referred to in the following sections simply as the vector grid) is a collection of 100 foot by 100 foot polygons covering the City of Redlands. The vector grid was created using Hawthe's Tools for Analysis, and originally resulted in a rectangular vector grid which covered an area equal to a rectangle whose sides were tangent to the far-most north, east, south, and west areas of Redlands. In order to avoid skewing the results of the statistical testing, and to properly represent the area on which the operationalized factors had an impact, the vector grid was clipped to the boundary of the City of Redlands.

When the feature classes were overlaid with the blank vector grid, some grids might contain two categorical values. Since the grid size was very small and there were a large number of grid cells for statistical testing, the accuracy of a small amount of cells was not critical. Therefore, the first value that fell into the grid was chosen as the final value of the cell.

Two factors-lighting and income-were added to the vector grid differently than the other factors. For the lighting factor, vector grid cells within 50 feet of the light points were selected and coded as one. All other cells were coded as zero. For the income factor, the Intersect tool was used to apply the census data to the vector grid. This process sliced some of the grid cells, which was corrected using the Dissolve tool. The cells that were sliced by the intersect tool had different values for income, so these were merged statistically using the "FIRST" function in the merge tool, which assigns the entire cell the value of whichever half of the split cell is processed first. This is acceptable because the accuracy isn't terribly affected due to the small 100 foot by 100 foot cell size, as compared to the generalized census tract level income data. Quantile classification was used to reclassify the income data into three categories with relatively equal numbers of units in each category. Equal cell sizes means relatively equal areas were represented in each category. Figure 5-2 displays the area effects that were implemented for each potential risk factor. 


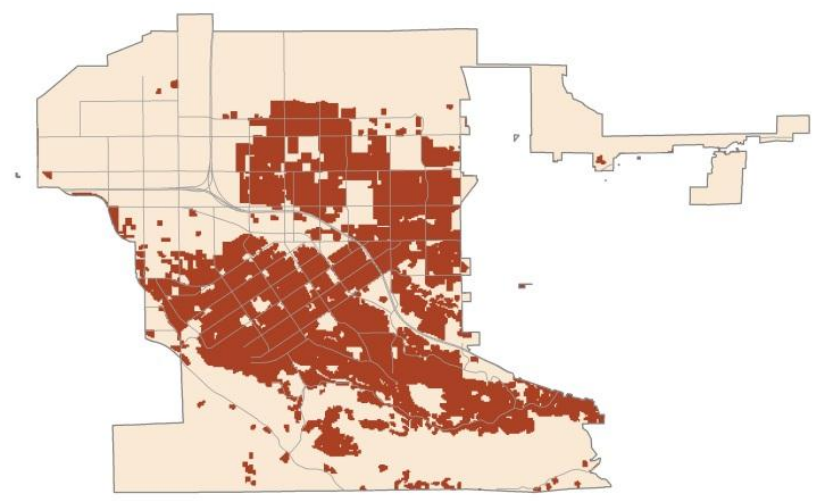

\section{Residential Land Use}

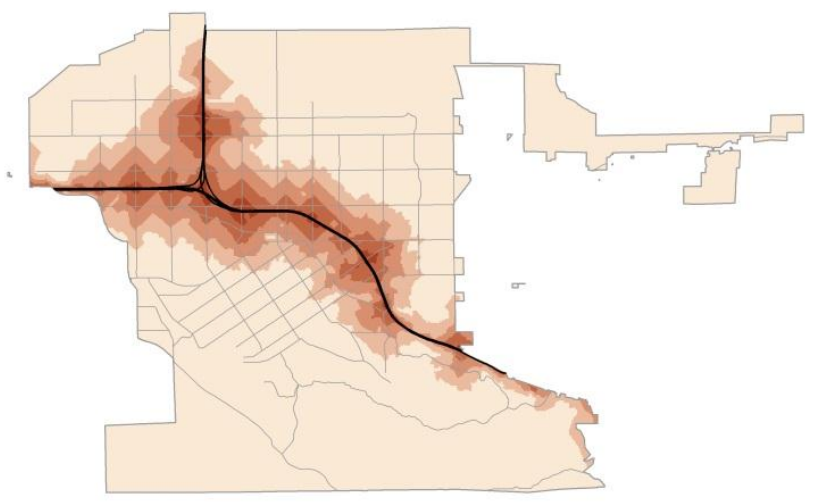

\section{Access to Freeway}

\section{— Freeway \\ Distance from Highway Exit}

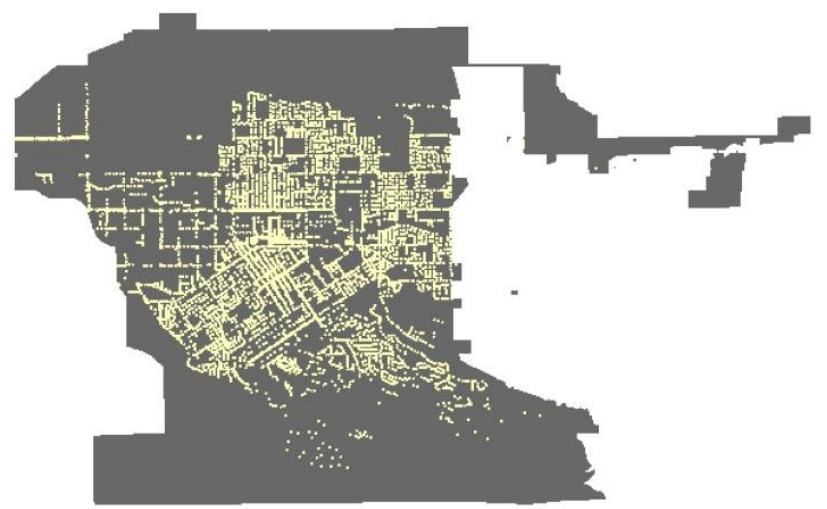

\section{Lighting \\ Cell without street ligh street light}
0.75 - 1 mile
$0.5-0.75$ mile
0.25 - 0.5 mile
$0-0.25$ mile

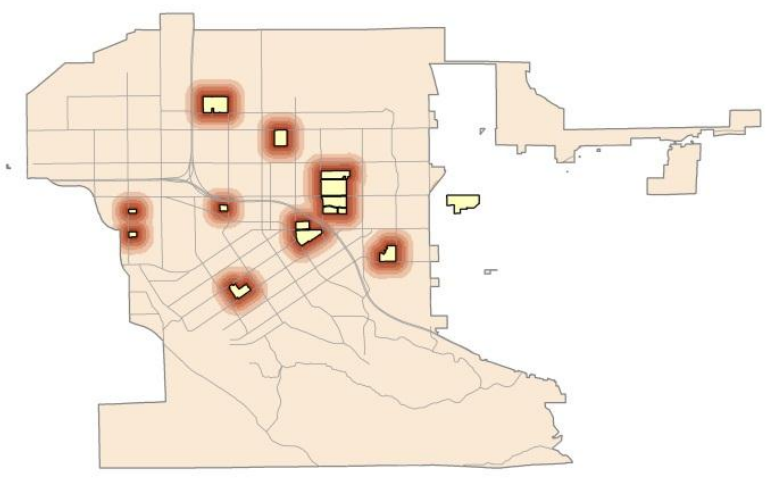

\section{Proximity to Schools}

Figure 5-2: Factor Area Effects 


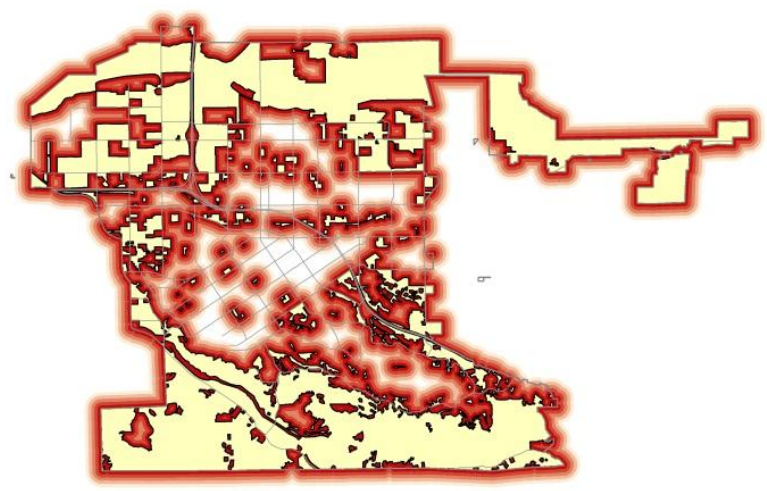

\section{Proximity to Groves or} Vacant Lots

$\square$ Grove or Vacant Lot Distance from Groves or Vacant Lots $1,056 \mathrm{ft}-0.25$ mile 792 - 1,056 feet $528-792$ feet

$264-528$ feet

0 - 264 feet

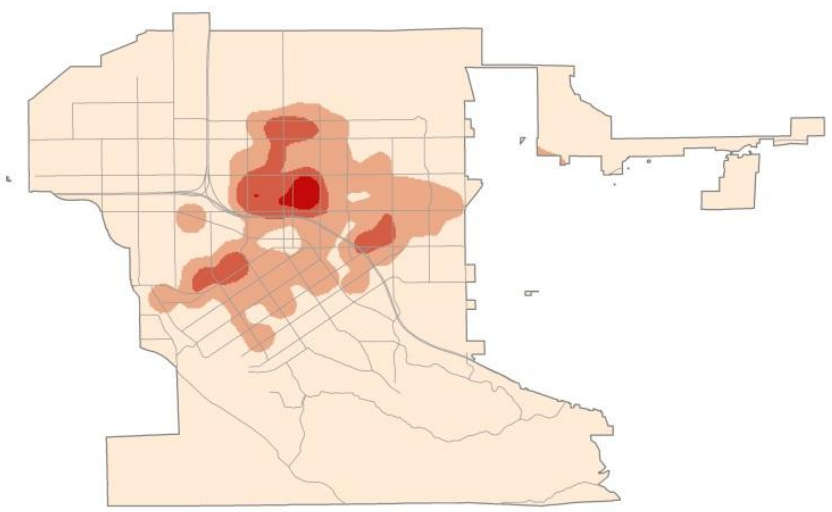

\section{Proximity to Arrestees}

\section{Arrestee Kernel Density}

0 - 480 arrestees

$480-1,800$ arrestees

$1,800-4,800$ arrestees

4,800 - 10,100 arrestees

\section{Income}

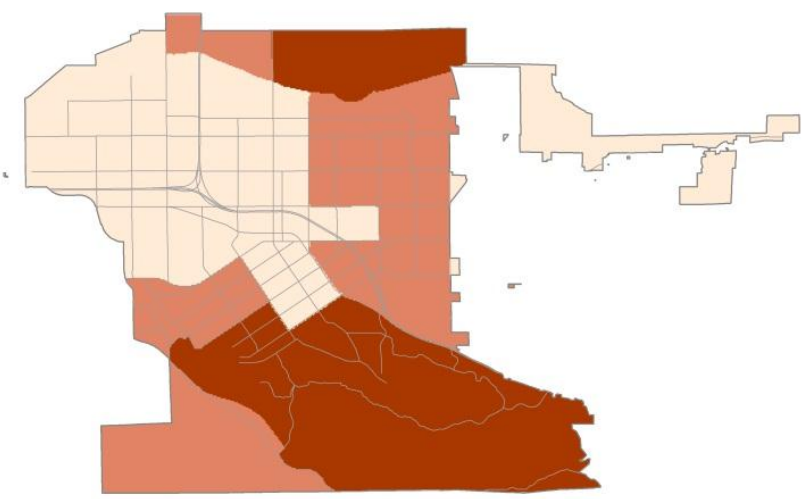

Median Household Income (Per Year)

Less than $\$ 66,815$

$\$ 66,815$ - $\$ 105,683$

Greater than $\$ 105,683$

\section{Proximity to Pawn Shops}

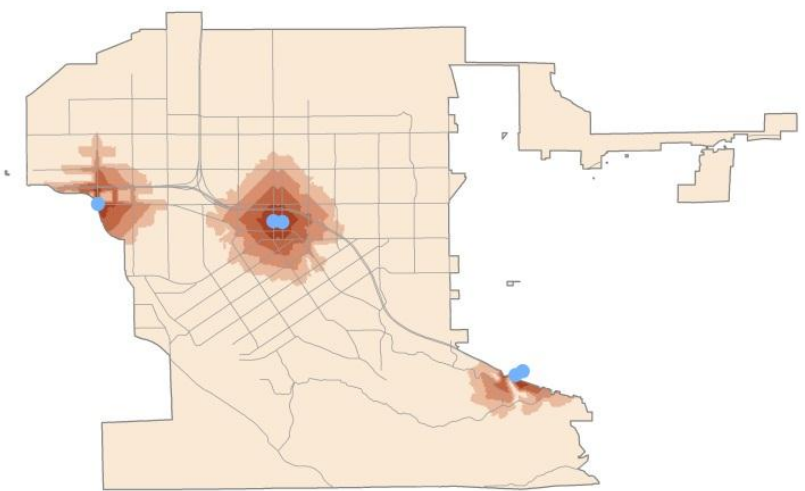

Distance from Pawn Shop

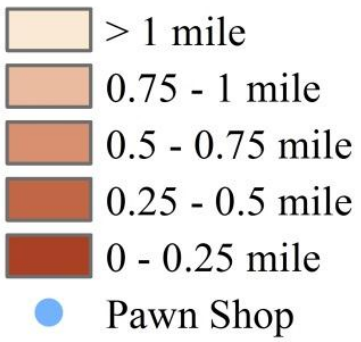

Figure 5-2 Continued 


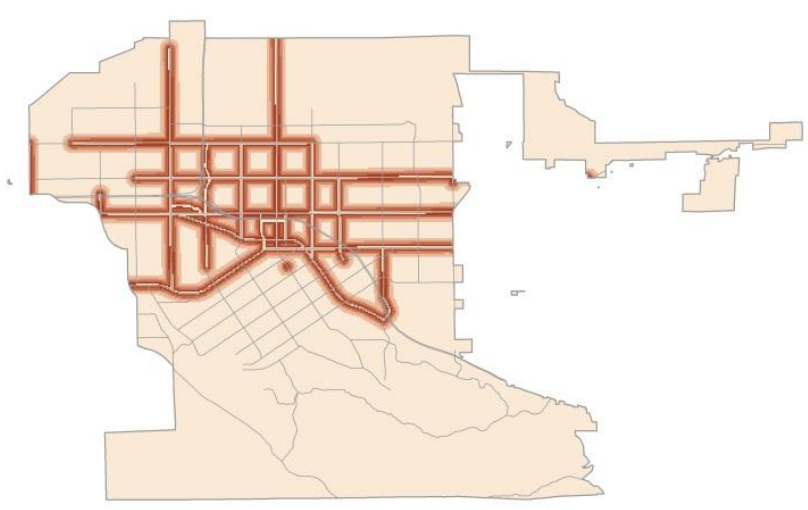

\title{
Proximity to Thoroughfares
}

Distance from Thoroughfare

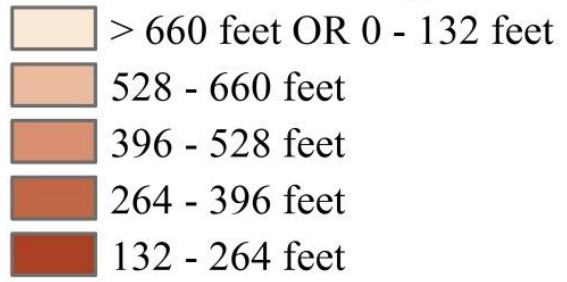

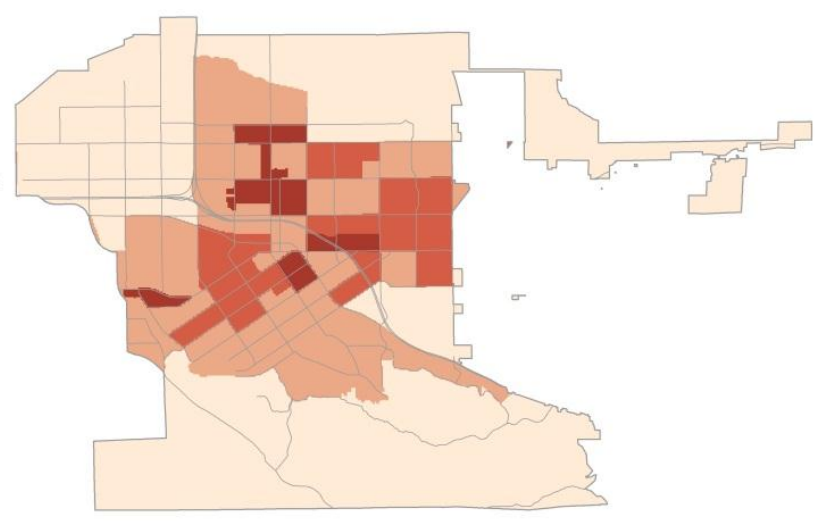

\section{Population Density}

\author{
People per square mile \\ 9 to 1,711 \\ 1,712 to 4,413 \\ 4,414 to 8.121 \\ $>8,122$
}

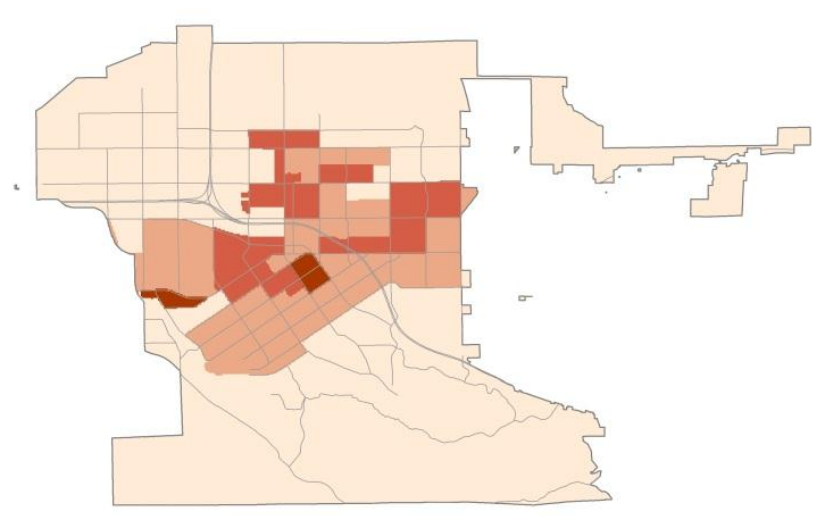

\section{Household Density}

Households per square mile

3 to 786.9

787 to $1,936.9$

1,937 to $3,450.9$

3,451

Figure 5-2 Continued

\subsection{Factor Correction}

Once the risk factors were operationalized in the vector grid, a Chi-square test on crosstabulation tables was conducted for each risk factor to examine whether they had a significant correlation with the occurrences of residential burglaries. While almost all of the factors proved to be statistically significantly correlated to residential burglary, four of the factors were modified to represent a binary version of the risk factor. In the Risk Terrain Modeling Manual, the factors were operationalized using a binary 
implementation. Figure 5-3 demonstrates the binary versions of the four distance-based factors that passed the Chi-square test.

Access to Freeway

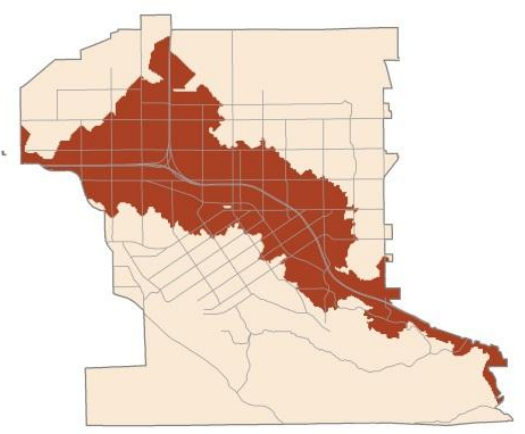

Proximity to Pawn Shops

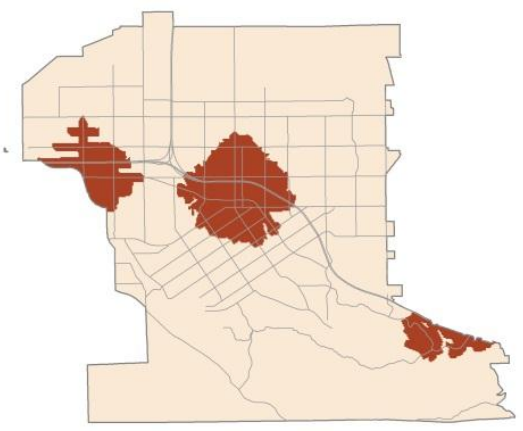

\section{Proximity to Schools}

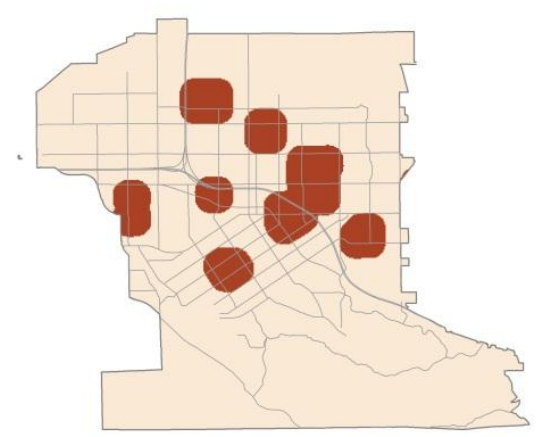

Proximity to Thoroughfares

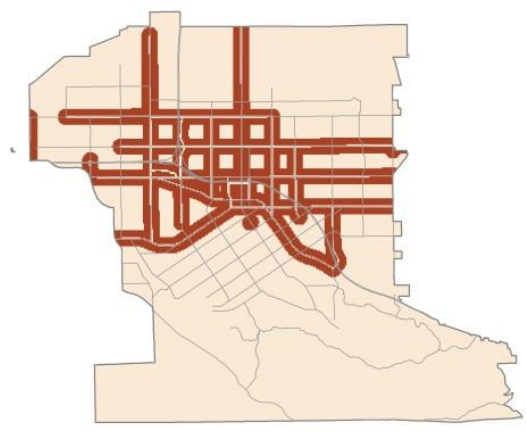

Binary Value

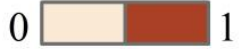

Figure 5-3: Binary Implementation

\subsection{Factor Normalization}

The final step in the factor creation process was normalization and conversion to raster format. In addition to the adjusted factors, other factors were also normalized between the values of zero and one to allow the overlay analysis in the later stage. Equations 5-1 and 5-2 show the formula used in the normalization.

Equation 5-1: Factor Normalization for Positive Relationship

$$
\frac{\text { value }-\min }{\max -\min }
$$

Equation 5-2: Factor Normalization for Negative Relationship

$$
\frac{\text { value }-\max }{\min -\max }
$$


Equation 5-1 was used to normalize factors that have a positive relationship with residential burglaries, which includes population density and proximity to arrestees. Equation 5-2 was used to normalize the variable that had a negative relationship with residential burglaries, which was income. Once all of the factors were normalized, they were converted to raster format using the Polygon to Raster tool in ArcGIS Toolbox.

\subsection{Tool Interface}

The RTM tool interface was designed to be easily navigable by the user. Figure 5-4 shows the final tool interface. Tool functionality and design decisions are discussed in this section.

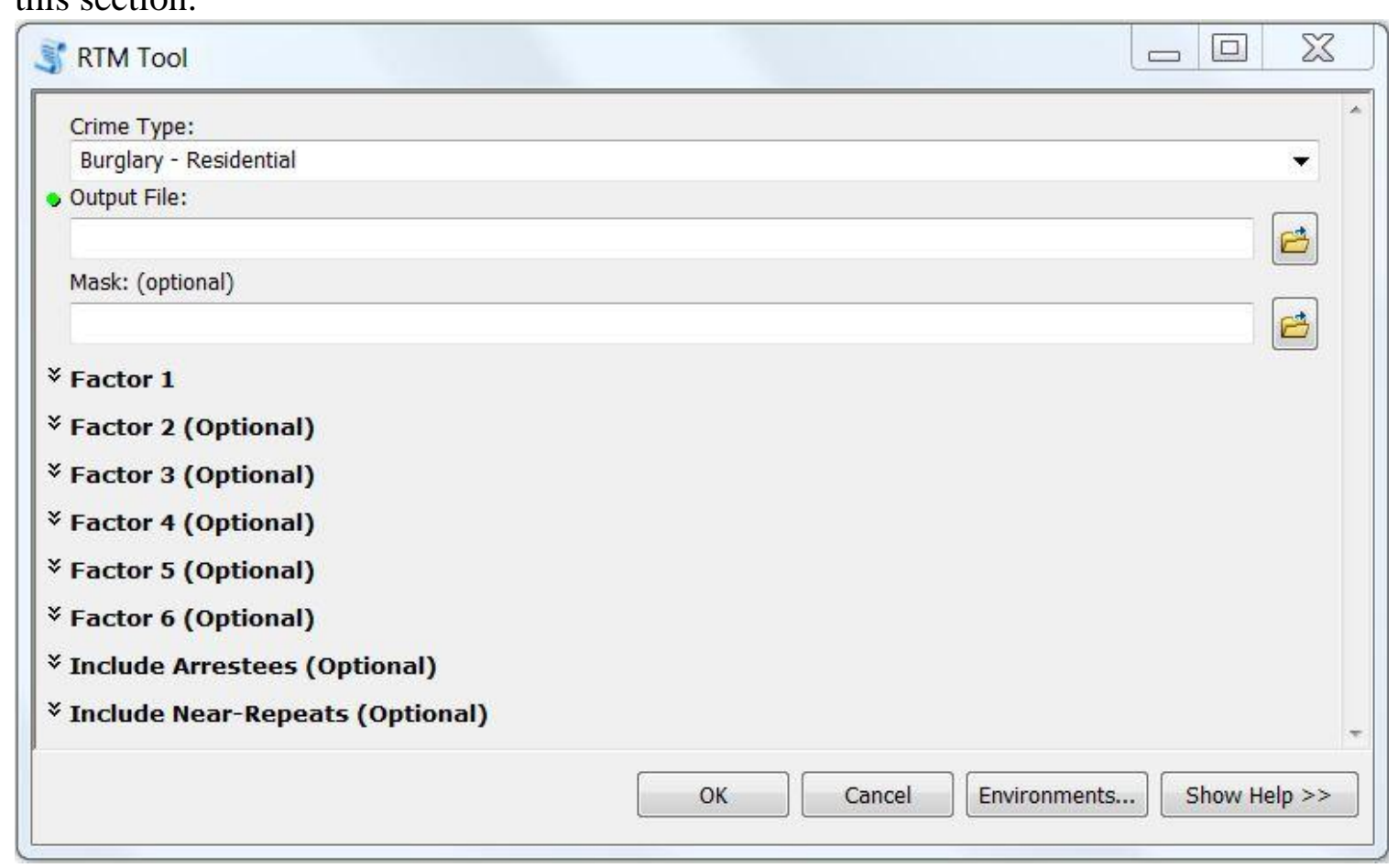

Figure 5-4: RTM Tool Interface

The interface consists of five major components: crime type selection, output raster file location, filter selection, static factor selection, and dynamic factor selection. Each of these components are discussed in the following sections.

\subsubsection{Crime Type Selection}

The crime type dropdown is populated with five separate crime types. Each of the five crime types were requested to be included by the client. The five crime types are assaults, commercial burglaries, residential burglaries, vandalism, and vehicle related crimes. Choosing a crime type is a required input and the crime types in the dropdown list are formatted to match the syntax of how the crime type is recorded in the city's incident database. The crime type dropdown is automatically set to residential burglary, as that is the crime type studied in this project. 


\subsubsection{Output Raster File}

The output of the tool is a raster file in which all specified risk factors are overlaid using map algebra. The final risk surface is normalized between values of zero and ten to allow for easy comparison of the risk surfaces for different crime types or final risk surfaces previously produced. The output is set to overwrite any previously saved rasters with an identical file name. The output section of the help file recommends a naming convention to avoid unintentional loss of previously generated surfaces.

\subsubsection{Mask Selection}

A masking option is included in the interface in order to allow the user to exclude any areas from the output raster where the crime being studied cannot occur. For example, a residential burglary can only occur in areas where there is residential land use. The input for the mask must be a binary raster dataset indicating where crimes may possibly occur, and where they cannot occur.

\subsubsection{Static Factor Selection}

Following the mask are the inputs for the static factors produced during the factor operationalization process. The tool allows six factor surfaces to be included in the model. Limiting the inputs is suggested in the RTM Manual, which states that in many cases, fewer factors produce models with higher accuracy than models with a higher number of input factors (Caplan \& Kennedy, 2010). This is likely related to the knowledge required to choose the correct risk factors. Better to include only a few wellresearched factors whose influence on the crime being studied is understood rather than twenty poorly understood factors.

At least one static factor is required to run the model. When the tool is initially opened, the static factor inputs are collapsed. Figure 5-5 demonstrates the factor input layout when expanded.

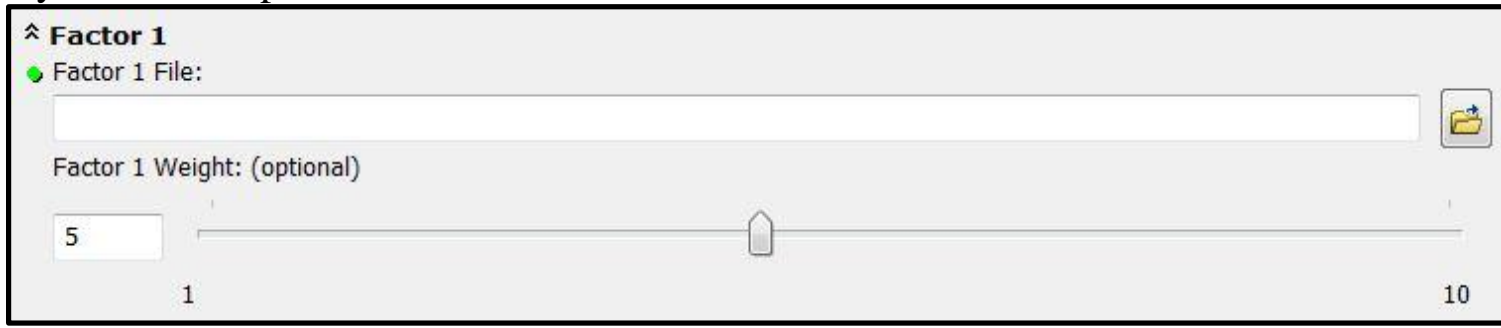

Figure 5-5: Expanded Factor Input

Each factor file allows the user to choose from available operationalized raster surfaces. The weights associated with each factor are optional. Weights are set to a default value of five, which the user may increase or decrease corresponding to the perceived or predicted influence of the factor on the crime type under consideration. 


\subsubsection{Dynamic Factor Selection}

The remainder of the inputs on the RTM tool interface are for the inputs of dynamic risk factors-Arrestees and Near-Repeats-which vary with specified duration (Figure 5-6).

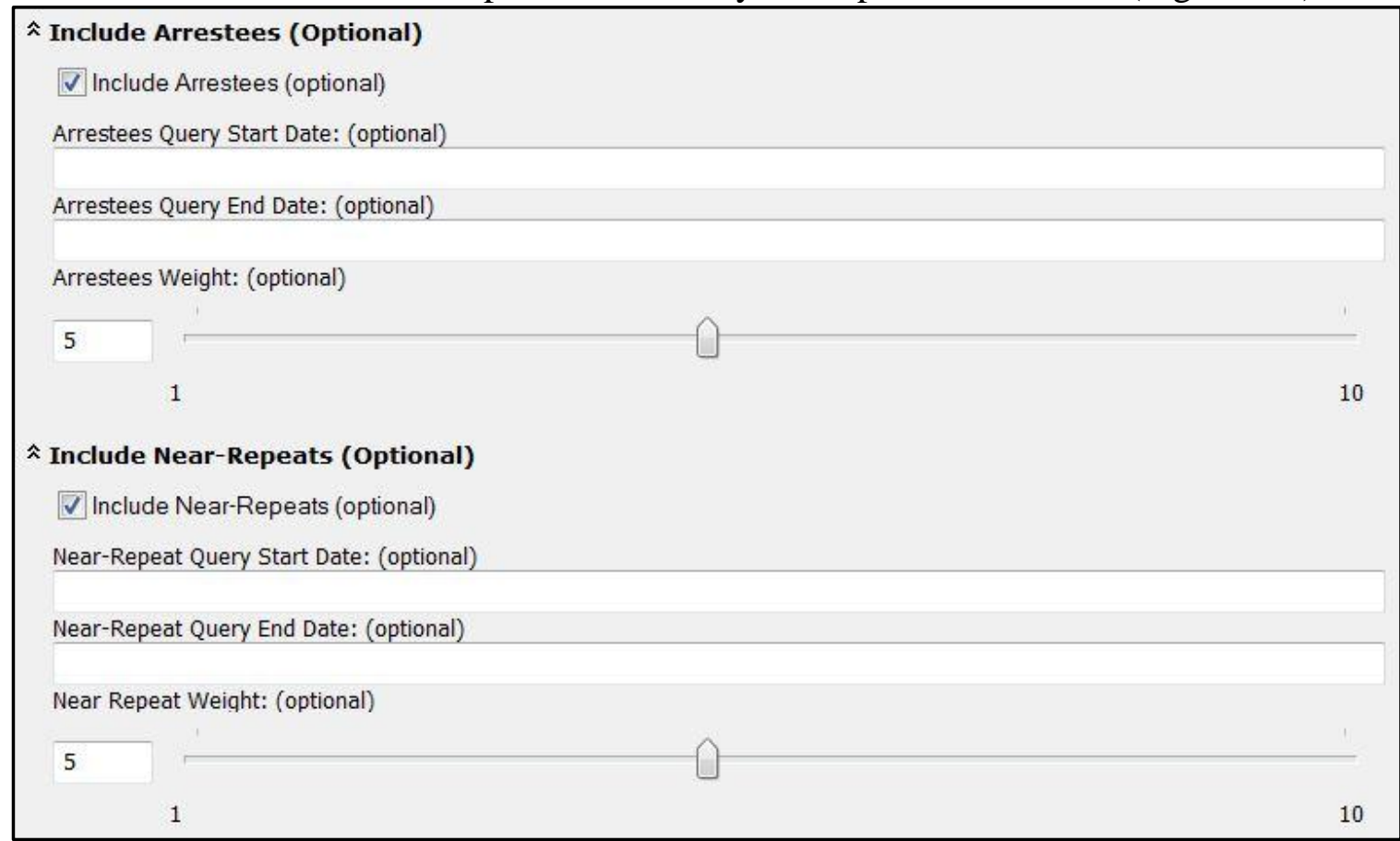

Figure 5-6: Expanded Dynamic Factor Selection

The check boxes for "Include Near Repeats" and "Include Arrestees" allow the user to choose whether or not either of these factors will be included in the model. They are represented as hard-coded factors because both are linked to databases that are updated by the City of Redlands. The risk factor surfaces for both the arrestees and nearrepeats options are generated on the fly within the model based on the temporal queries specified by the user.

For the near-repeat factor, the incidents that meet the user-input query requirements are buffered with a distance of a quarter mile. It is then overlaid with the blank vector grid to create a binary vector grid where the buffered area is assigned a value of one and the area outside the buffer is assigned a value of zero. Finally, the vector grid is converted to a raster surface according to the populated values. For the proximity to arrestees factor, a simple buffer around each home address does not work appropriately, as there are often many arrestees within the specified time frame. The aggregate of buffers generated from each arrestee home address covers most of Redlands. This does not accurately reflect the variation in risk present over the entire city, so a kernel density is used to represent the spatial distribution of recent arrestees. The kernel density output is normalized between values of zero and one.

The queries give the user control over the specific time period used to query the database and produce the surface. If no dates are specified and the factor is checked to be included, the system defaults to querying the specified crime type for occurrences within the past month for near-repeats and arrestees arrested within the past two years home 
addresses. Additionally, the user may weight each factor to properly represent the importance of these factors relative to the other risk factors.

\subsection{Process}

This section details the components of the tool. The Python script is located in Appendix A for reference. The codes behind the tool interface consist of four primary processes. The first is importing of necessary Python modules and data, and configuring the environment settings. At this stage, all of the static risk factors, as well as the corresponding weights specified by the user, are imported to the model. The specified mask layer is also recognized by the model for use in the map algebra process.

The second process of the tool queries and produces workable raster surfaces for the near-repeats and proximity to arrestees factors from the dynamic databases, if these two factors are chosen to be included in the model. The generated raster surfaces are to be used in the map algebra process, as well.

The third process performs map algebra to produce a raw raster output of the combined factors that are in raster format. The Raster Calculator available in ArcGIS Toolbox was originally intended for use to combine the risk factor layers. Because the tool was coded in Python, however, this tool was not used. A weighted addition is directly performed on the input raster surfaces. Figure 5-7 shows the conceptual equation used to combine the input rasters.

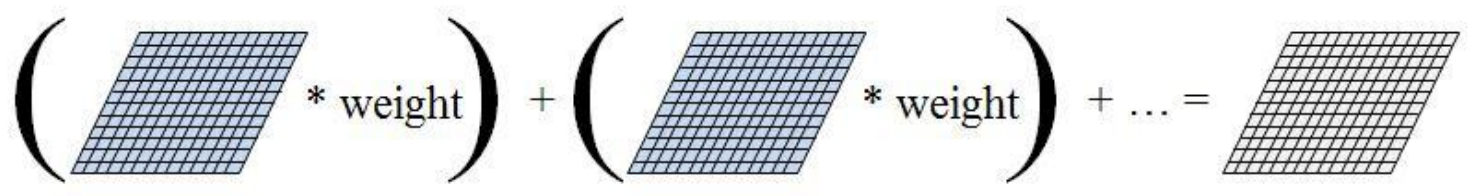

Figure 5-7: Map Algebra

As discussed earlier, the tool is limited to six static risk factors. If near-repeats and/or recent arrestees are included, there may be a total number of eight input surfaces in the computation. If a mask is included in the model, the entire equation is multiplied by the mask raster. Because the mask raster must be binary-either one or zero-output risk values in areas where the crime type may occur remain unchanged, while risk values where the crime type cannot occur are reduced to a value of zero. If no mask is specified the entire raster is multiplied by one, thus not affecting the output.

The last process of the tool normalizes the raw output raster and saves this final output to the filename specified. The raw output raster contains values that increase from zero to as high as eighty, although a number as high as eighty is unreasonable and should prompt the user to reexamine the chosen weighting scheme. These values are normalized at the end of the script to values between zero and ten to allow the final output raster to be easily compared to other completed RTM tool outputs. Map algebra is used again in this step to execute the normalization on the raw output raster. In this case, the raw output raster is the only input raster along with the minimum and maximum cell values within the raster to compute the normalized value for each cell. 


\subsection{Summary}

In this chapter, the operationalization of area effects for each residential burglary risk factor was discussed. The format of the input rasters for the Risk Terrain Modeling Tool was described. The final tool interface was presented, with an explanation of each of the input sections. The major processes occurring in the Python script when the tool is run was described, and specific scripting choices were defended. 


\section{Chapter 6 - Results and Analysis}

This chapter details the statistical tests for input risk factors, as well as the model output. Initial crosstab and Chi-square significance tests on the potential risk factors are explained. The final output is presented and validity of the model is discussed based on the binary logistic regression result.

\subsection{Chi-square Test}

As discussed in Chapter 5, the second step in preparing the factors for use as inputs in the model was to test which risk factors significantly correlated with previous occurrences of residential burglaries. The Chi-square test on crosstabulated variables was used to test the independence of residential burglary and each of these risk factors. The test was performed with the 100 by 100 foot vector grid cells-discussed in Chapter 5-using SPSS 19. Only grid cells that intersect with residential land use were used in statistical testing.

A dataset depicting the locations of past burglaries (primarily 2006 through 2011, with a few additional burglaries in previous years) was added to the vector grid (Figure 6$1)$.

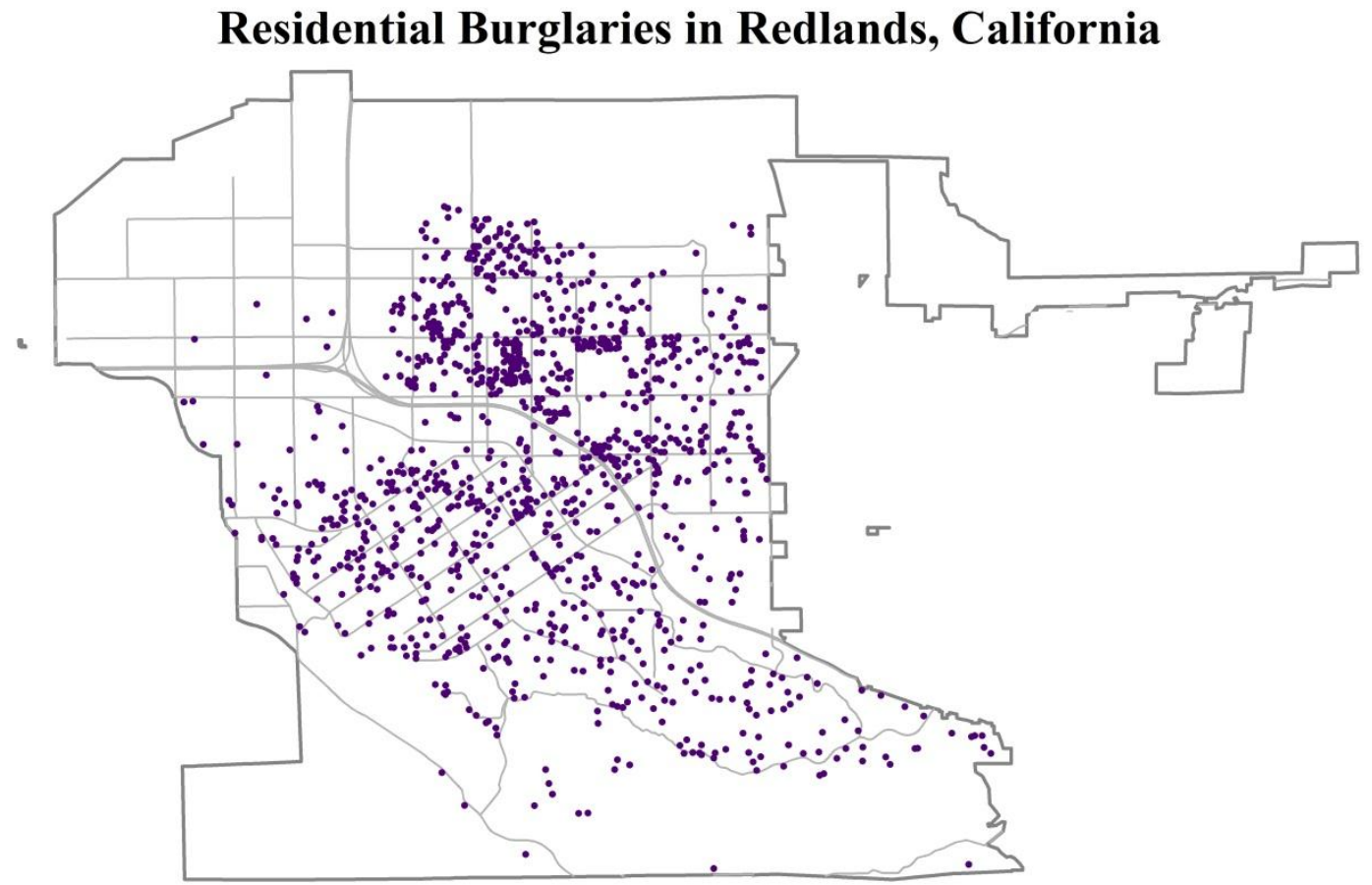

Each $\cdot$ represents one residential burglary

\section{Figure 6-1: Past Residential Burglaries}

Each cell in the vector grid has the presence (1) or absence (0) of residential burglary as one column attribute, and the area effects of each risk factor variable as other attributes. There were a total of ten risk factors tested, and all of them except for lighting turned out to be significantly correlated with residential burglaries (Table 6-1). Two 
factors-lighting and areas adjacent to wooded areas or vacant lots-were significantly correlated, but did not meet a second criteria for inclusion in the model outlined by the Risk Terrain Modeling manual. This second criterion is discussed in the following access to freeway example. It is worth noting that these risk factors may be correlated among themselves and therefore this issue might need to be addressed in the final overlay analysis.

Table 6-1: Factor Status

\begin{tabular}{|l|c|}
\hline \multicolumn{1}{|c|}{ Potential Factor } & $\begin{array}{c}\text { Significantly Correlated to } \\
\text { Residential Burglaries }\end{array}$ \\
\hline Access to freeway & \\
\hline Lighting & \\
\hline Proximity to schools & \\
\hline Areas adjacent to wooded areas or vacant lots & \\
\hline Proximity to arrestees & \\
\hline Income & \\
\hline Proximity to pawn shops & \\
\hline Proximity to thoroughfares & \\
\hline Population Density & \\
\hline Household Density & \\
\hline
\end{tabular}

Since the interpretations of the Chi-square test outputs for these ten risk factors are similar, only the test output on proximity to freeways is presented here. Other outputs are listed in Appendix B.

Table 6-2 shows the crosstabulation of residential burglaries and access to freeways. The Chi-square test compares the frequency of each cell against the expected frequency under the assumption of independence. The significance value of $p<0.01$ indicates that freeway access is significantly correlated with the occurrence of residential burglary. In addition, Caplan and Kennedy (2010) also suggest that the factor should be deemed as an influencing factor only if the percentage of the cells that have both crime events and the risk factor is greater than the cells with that risk factor but no crime events. In this test, about $40 \%$ of the grid cells that experienced residential burglary were close to freeways. This number is greater than the $30 \%$ of cells where the risk factor is present, but no residential burglaries occurred. Combining these two criteria, access to freeway is a significant factor for residential burglaries.

Table 6-2: Proximity to Freeway Access * Residential Burglary Crosstabulation

\begin{tabular}{|c|c|c|c|}
\hline \multicolumn{2}{|c|}{} & \multicolumn{2}{c|}{ Residential Burglaries } \\
\cline { 3 - 4 } & No & Yes \\
\hline $\begin{array}{c}\text { Proximity to Freeway } \\
\text { Access }\end{array}$ & No & $70.0 \%$ & $59.2 \%$ \\
\cline { 3 - 4 } & Yes & $30.0 \%$ & $40.8 \%$ \\
\hline
\end{tabular}

$(\mathrm{p}<0.01)$ 


\subsection{Final Model}

Although the Chi-square test results suggested that the seven risk factors were significantly correlated to residential burglaries, the RTM tool allows the user to select the most important factors for the time period under consideration. In order to find an appropriate combination of these factors for the model, a hypothetical test date was used. The test date chosen was September 1, 2010. From this date, arrestee home addresses from the past two years (September 1, 2008 through September 1, 2010) were queried to generate the proximity to arrestees surface within the model. The three previous months of residential burglaries (June 1, 2010 through September 1, 2010) were also queried from this date to create the near-repeats risk factor surface. The resulting model was tested with the following four months, September 1, 2010 through January 1, 2011, of future residential burglaries.

The first attempt was to include all the significant factors with the two dynamic factors into the model. However, the model output turned out to be a poor fit for the future test residential burglaries. This could be because the correlation of these factors with residential burglaries may change over time and collinearity may exist among these risk factors. To find a model that could appropriately predict the future residential burglaries, the impact of each risk factor on the future residential burglaries was examined through binary logistic regression. The testing results showed the two dynamic factors are the only significant factors for the testing duration. This indicated that these arrestees and past residential burglaries may be strong surrogates for other factors. Meanwhile, a number of combinations of these factors and weights were used to predict the risk surface. Binary logistic regression was performed for each risk surface to test the validity of the model and compare the model fitness (see Section 6.3 for details).

Based on the results of these test combinations, the final model recommended that three risk factors be included, as shown in Table 6-3.

\section{Table 6-3: Final Test Model Inputs}

\begin{tabular}{|c|c|c|}
\hline Factor & Weight & Query Time Period \\
\hline Near-Repeats & 5 & June 1, 2010 - September 1, 2010 \\
\hline Proximity to Arrestees & 5 & September 1, 2008 - September 1, 2010 \\
\hline Proximity to Pawn Shops - Binary & 1 & Not Applicable \\
\hline
\end{tabular}

This combination produced a significant result with the highest predictive accuracy of all combinations tested. That a small number of factors could produce a more accurate output than a model with a higher number of potential factors was not surprising, as it was noted in the RTM manual (Caplan \& Kennedy, 2010). The mask for only residential land use was applied using the masking portion of the tool. Figure 6-2 shows the final output risk surface for residential burglaries, as calculated from the test periods and the actual residential burglaries in the future. Although there are some discrepancies between the actual crime and the predicted risk, almost half of the crime incidents were located in areas indicated as high risk in the model (greater than one standard deviation above the mean output cell value). To assess the validity of the model binary logistic regression was used, which will be described in the following section. 


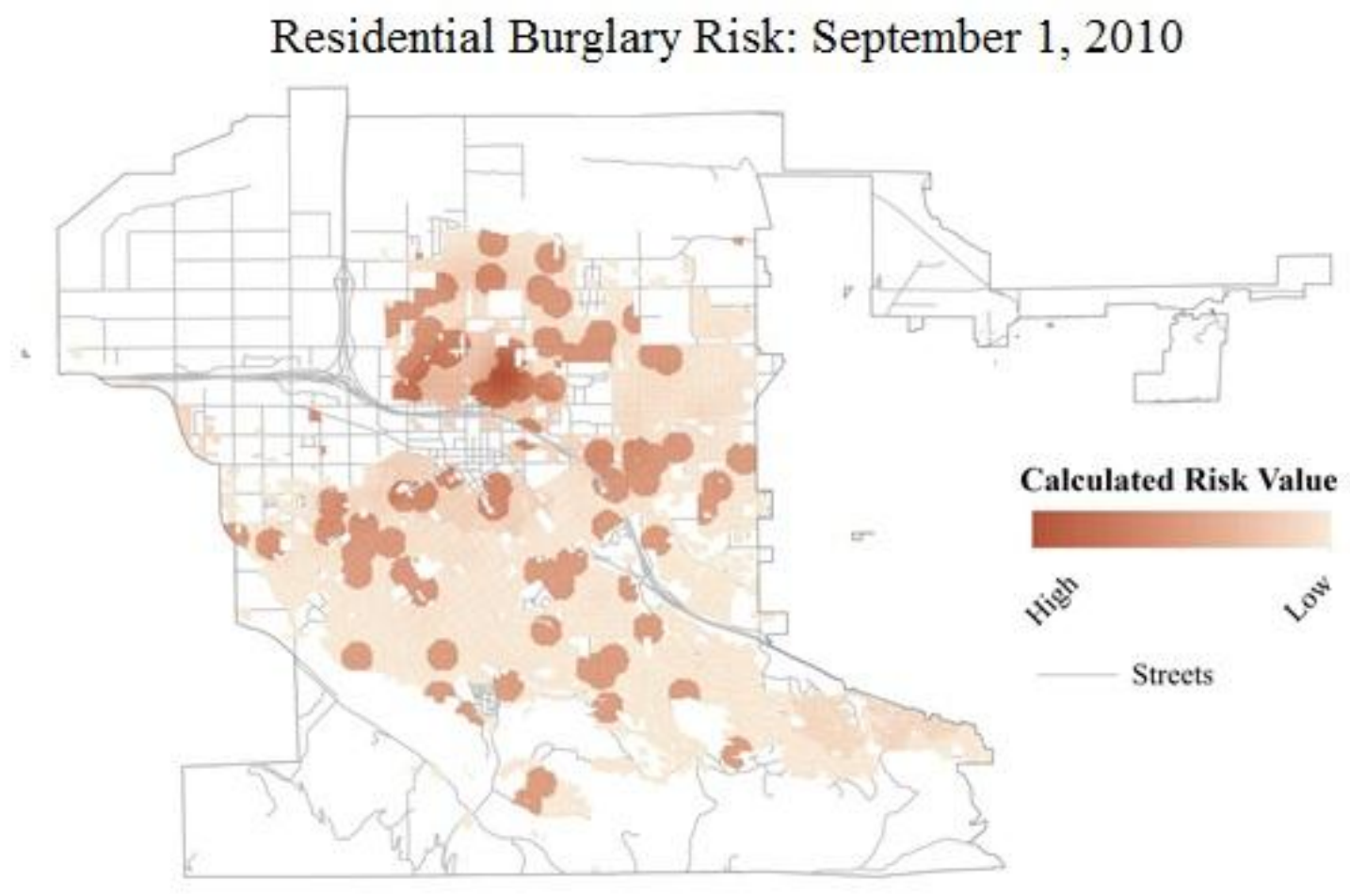

Figure 6-2: Final Model Output

\subsection{Model Validity Test}

Binary Logistic Regression was used to test the output of the RTM tool for statistical significance. In this section, preparation of the output raster for regression testing is discussed, followed by the results of the final regression test.

\subsubsection{Output Preparation}

The raster output from the RTM tool needed to be prepared for statistical testing. The output preparation process is outlined in Figure 6-3.

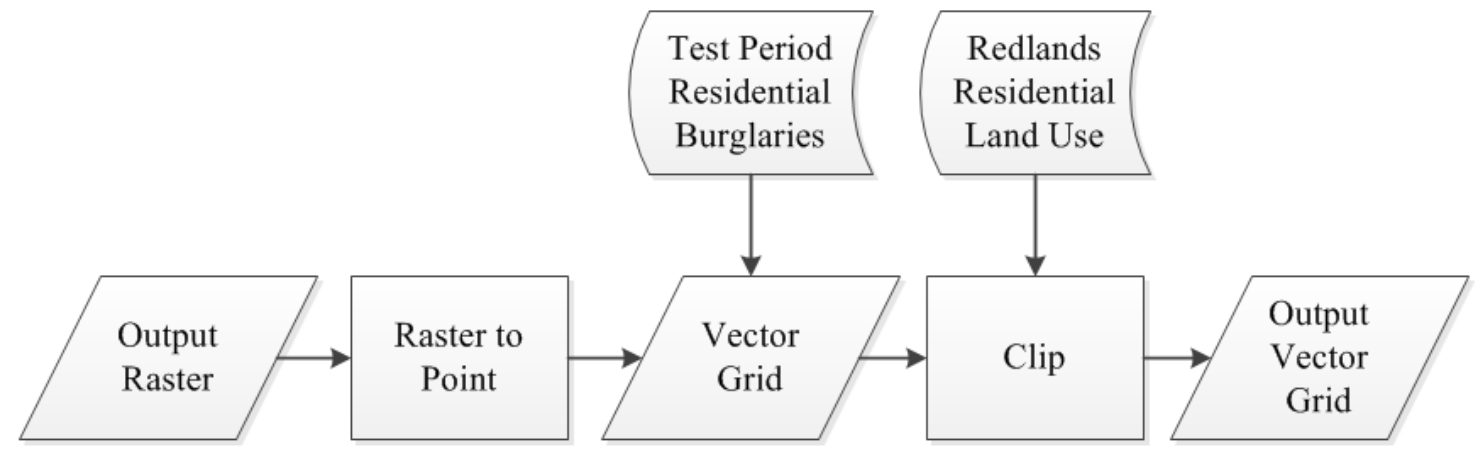

Figure 6-3: Output Preparation for Regression Test

First, the output RTM tool raster was converted to points representing the value in each cell. The points with the output cell values were then added to a new blank vector 
grid of the Redlands study area using the Spatial Join tool. Attention was paid during both of these steps to ensure that the cell values remained in a float format, and were not converted to integer format. Next, a new attribute representing presence or absence of residential burglary was added to the vector grid. Cells that intersected with residential burglaries that occurred between September 1, 2010 and January 1, 2011 were coded as one, while cells that did not intersect with a residential burglary that occurred during that time frame were coded as zero. Finally, because residential burglaries theoretically only occur in areas of residential land use, the output grid was clipped to those areas so as not to skew the regression test output. The clip was performed by selecting whole grid cells that intersect with residential land use areas, and exporting the cells as a new feature class.

The data may be tested in this format (after converting the burglary count field to only values of zero and one), but will likely yield a poor regression result due to the high number of cells coded zero in which no residential burglaries occurred. Because the number of cells where residential burglaries did not occur was so much higher than cells where residential burglaries did occur, the R-square result was very low. To correct this, the data were aggregated to census blocks, a common aggregation unit. The following steps outline the process of aggregating the vector grid produced in the previous step into larger census block units:

1. Clip blocks to residential land use.

2. Use the Union tool to merge the output vector grid and clipped blocks feature classes.

3. Export resulting polygons of union tool that are within the clipped blocks.

4. Dissolve the exported file by the unique identifier for each block, adding the output raster value (default grid_code) as a field in the new feature class using the maximum summarization.

5. Add a field to the dissolve tool output, code field as one for blocks that intersect with the test period residential burglary points and zero for blocks that do not intersect with the test period residential burglary points.

6. Export the attribute table as a .dbf file for statistical testing in SPSS.

The resulting .dbf file can be loaded into SPSS for regression testing.

\subsubsection{Binary Logistic Regression Test}

Binary logistic regression was performed on the aggregated output risk surface to test the predictive validity of the model. Logistic regression was chosen because the dependent variable (residential burglary) is binary (either one or zero). The independent variable, the output cell value, is continuous. The regression results are displayed in Table 6-4.

\section{Table 6-4: Final Regression Analysis Results}

\begin{tabular}{|c|c|c|c|c|}
\hline Variable & B & Standard Error & Significance & $\operatorname{Exp}(\mathbf{B})$ \\
\hline Cell Value & 0.188 & 0.044 & 0.000 & 1.207 \\
\hline
\end{tabular}

The significance of $\mathrm{p}<0.01$ indicates that the predicted risk value of a cell can significantly affect the likelihood of having residential burglaries in this cell. Specifically, the odds ratio $(\exp (B))$ indicates that for every one unit increase in the output risk 
surface, the likelihood of residential burglary occurrence increases by approximately twenty percent.

The Nagelkerke R-square value for this model is $4.4 \%$. This is not a high number, but may be acceptable compared to the literature. In the study by Kennedy, Caplan, and Miller (2009), the final predictive model for shootings in Irvington, New Jersey had a Rsquare value of $11 \%$. However, the low R-square value indicates that model specification needs to be further explored. Section 6.4 details the limitations of predicting residential burglaries using the RTM.

\subsection{Discussion}

Throughout the process of researching, developing, and implementing RTM in an ArcGIS tool with residential burglaries as a case study, two factors were identified that can severely affect the predictive validity of the model: identifying relevant risk factors, and operationalizing them. It is possible that some risk factors are location specific and therefore may not be well studied in the literature. In this project, local knowledge provided by the Police Department was considered with statistical testing. In the modeling process, operationalizing these potential risk factors was also critical, because the factors would be ineffective if the spatial representation could not portray the correct risk with respect to the crime type.

This led to the major limitation of the final predictive model for residential burglaries; data corresponding to why a burglar may chose a particular neighborhood or house is not available. The physical appearance and layout of a home can influence its chances of being burgled. Factors such as lighting, vegetation, security systems, dogs, and physical obstructions such as fences or walls may all contribute to what makes a house an appealing burglary target. These are only factors for which data could be collected. Other factors, such as indications that the residents may be away (mail piling up, overgrown grass) or the appearance of "hot item" boxes on the curb (indications that there are new items inside the home of interest to a potential burglar) can also influence a home's burglary potential. These potential factors would be nearly impossible to track. Therefore, the model fitness suggests that predicting residential burglary using risk terrain modeling is challenging. 


\section{Chapter 7 - Conclusions and Future Work}

Chapter 7 summarizes what was accomplished in the project, as compared to the original project goals and objectives. Ideas for potential future projects are also presented to build on the Risk Terrain Modeling Tool.

\subsection{Conclusion}

The primary focus of this project was to create an ArcGIS tool implementation of the Risk Terrain Modeling method, and showcase the functionality and predictive capability of the tool using residential burglary. If the police department wishes to increase patrols in neighborhoods most at risk of residential burglary, they can direct assets to areas displayed as high risk on the risk terrain modeling tool output surface.

The RTM tool allows the user to include as inputs both static risk surfaces and dynamic surfaces that are queried and produced within the tool. The user has the ability to specify date ranges for the dynamic surfaces. The interface developed in ArcGIS 10 is simple, despite being designed within the limits of the ArcGIS input parameter options. The tool runs at a reasonable speed, taking approximately a minute and a half when both dynamic inputs are selected.

A study on residential burglary in this project provided a sample process which the client may follow to generate additional crime surfaces, and was useful in validating the tool output.

\subsection{Future Work}

There are a few ways in which this project could be expanded for future work by using the tool to conduct additional analysis, expanding the tool, or integrating the tool into a separate study. The following sections outline potential future projects that build on the Risk Terrain Modeling tool.

\subsubsection{Incorporate Temporal Variables}

The capability to incorporate temporal variables or weights into the RTM tool would be an interesting addition to the tool's functionality. Currently, the RTM tool produces a risk surface that is accurate for the current date when the default time settings on the nearrepeat or arrestee factors are included, or for the user-specified dates. Many crime types are more likely to occur at a specific time of day or during certain months of the year. Incorporating these types of temporal variables would expand the tool's predictive capability and precision.

\subsubsection{Analysis of Other Crime Types}

In this project the RTM tool was only applied to residential burglaries. Application of the RTM tool to other crime types (including preliminary regression and chi-square tests, as done in this study) could possibly aid the police department by generating predictive models for other common crime types that occur within the city. 


\subsubsection{Evaluating Police Patrol Effectiveness}

If the RTM tool were used regularly by the police department, a study could be conducted to determine if crime occurrences or predicted risk values fall where police spend more time. This could be done by comparing GPS data from police cars with later crime rates and testing to determine if there is a statistically significant correlation. A negative correlation would validate the use of the RTM tool on an operational level. 


\section{Works Cited}

Atkins, S., Husain, S., \& Storey, A. (1991). The Influence of Street Lighting on Crime and Fear of Crime. London: Crime Prevention Unit.

Beavon, D. J., Brantingham, P. L., \& Brantingham, P. J. (1994). The Influence of Street Networks on the Patterning of Property Offenses. Crime Prevension Studies, 2, 115-148.

Caplan, J. M., \& Kennedy, L. W. (2010). Risk Terrain Modeling Manual. Newark, NJ: Rutgers Center on Public Security.

Caplan, J. M., \& Kennedy, L. W. (Eds.). (2011). Risk Terrain Modeling Compendium. Newark, NJ: Rutgers Center on Public Security.

City of Redlands. (n.d.). Organization. Retrieved April 16, 2012, from City of Redlands: A City that Works!: http://www.cityofredlands.org/police/organization

Corcoran, J. J., Wilson, I. D., \& Ware, J. A. (2003). Predicting the geo-temporal variations of crime and disorder. International Journal of Forecasting, 19, 623634.

Felson, M., \& Poulsen, E. (2003). Simple indicators of crime by time of day. International Journal of Forecasting, 19, 595-601.

Gorr, W., Olligschlaeger, A., \& Thompson, Y. (2003). Short-term forecasting of crime. International Journal of Forecasting, 19, 579-594.

Groff, E. R., \& La Vigne, N. G. (2001). Mapping an Opportunity Surface of Residential Burglary. Journal of Research in Crime and Delinquency, 38, 257-278.

Groff, E. R., \& La Vigne, N. G. (2002). Forecasting the Future of Predictive Crime Modeling. (N. Tilley, Ed.) Crime Prevention Studies, 13, 29-57.

Kennedy, L. W., Caplan, J. M., \& Miller, J. (2009). Applying Risk Terrain Modeling to Shootings in Irvington, NJ. Rutgers Center on Public Security.

Roncek, D. W., \& Faggiani, D. (1985, Winter). High Schools and Crime: A Replication. The Sociological Quarterly, 26(4), 491-505.

U.S. Census Bureau. (2012, January 31). State \& County QuickFacts. Retrieved April 16, 2012, from U.S. Census Bureau:

http://quickfacts.census.gov/qfd/states/06/0659962.html 



\title{
Appendix A. Python Script
}

\author{
\#Import related modules \\ import numpy \\ import arcpy \\ from arcpy.sa import * \\ import sys \\ import math \\ import re \\ import os
}

\#Overwrite output

arcpy.env.overwriteOutput $=$ True

arcpy.env.workspace $=$

"C:IUsers\sara_goetzlDocuments\MIP\RTMToollRTMDatabase.gdb"

\#Set input values

crimeType $=\operatorname{str}(\operatorname{sys} \cdot \operatorname{argv}[1])$

output $=$ sys. $\operatorname{argv}[2]$

\#Check if rasters exist, if not, assign 0

if (sys.argv[12]<>'\#'):

factor $1=$ Raster $(\operatorname{sys} . \operatorname{argv}[12])$

else:

factor $1=0$

if (sys.argv[14]<>'\#'):

factor2In $=$ Raster $($ sys.argv[14])

else:

factor 2 In $=0$ 


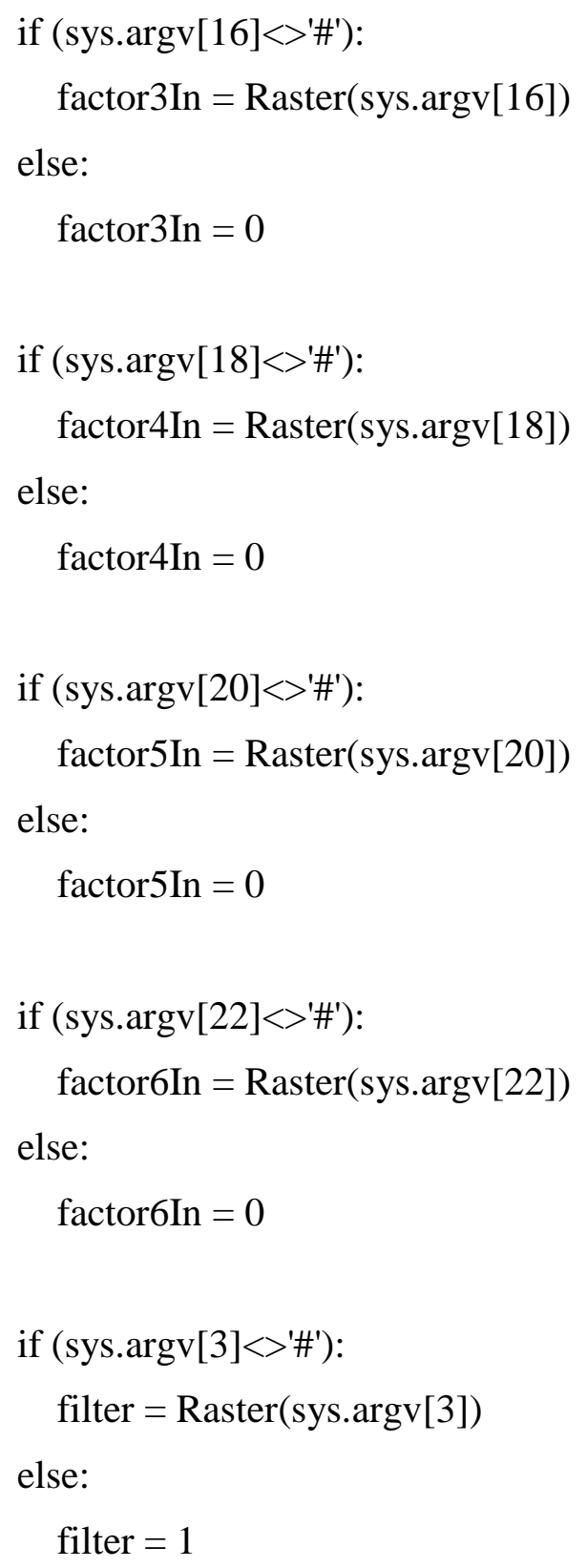


else:

factor $2 \mathrm{~W}=1$

if (sys.argv[17]<>'\#'):

factor3W = float(sys.argv[17])

else:

factor $3 \mathrm{~W}=1$

if (sys.argv[19]<>'\#'):

factor $4 \mathrm{~W}=$ float $(\operatorname{sys} . \operatorname{argv}[19])$

else:

factor $4 \mathrm{~W}=1$

if (sys.argv[21]<>'\#'):

factor $5 \mathrm{~W}=$ float $(\operatorname{sys} . \operatorname{argv}[21])$

else:

factor $5 \mathrm{~W}=1$

if (sys.argv[23]<>'\#'):

factor6W = float(sys.argv[23])

else:

factor6W = 1

if (sys.argv[7]<>'\#'):

repeatRiskW = float(sys.argv[7])

else:

repeatRiskW = 1

if (sys.argv[11]<>'\#'):

arresteeRiskW = float(sys.argv[11])

else:

arresteeRiskW = 1 
\#Get system time variables

arcpy.AddMessage("Retrieving system date...")

month = time.strftime ('\% $\%$ ')

day $=$ time.strftime('\%d')

yearIn = time.strftime ('\% Y')

\#Processing near repeats, if selected

if (sys.argv[4]<>'\#'):

arcpy.AddMessage("Processing near repeats...")

\#Getting near repeats date range. If specific date range is input, use those dates, if not, use current date minus one month.

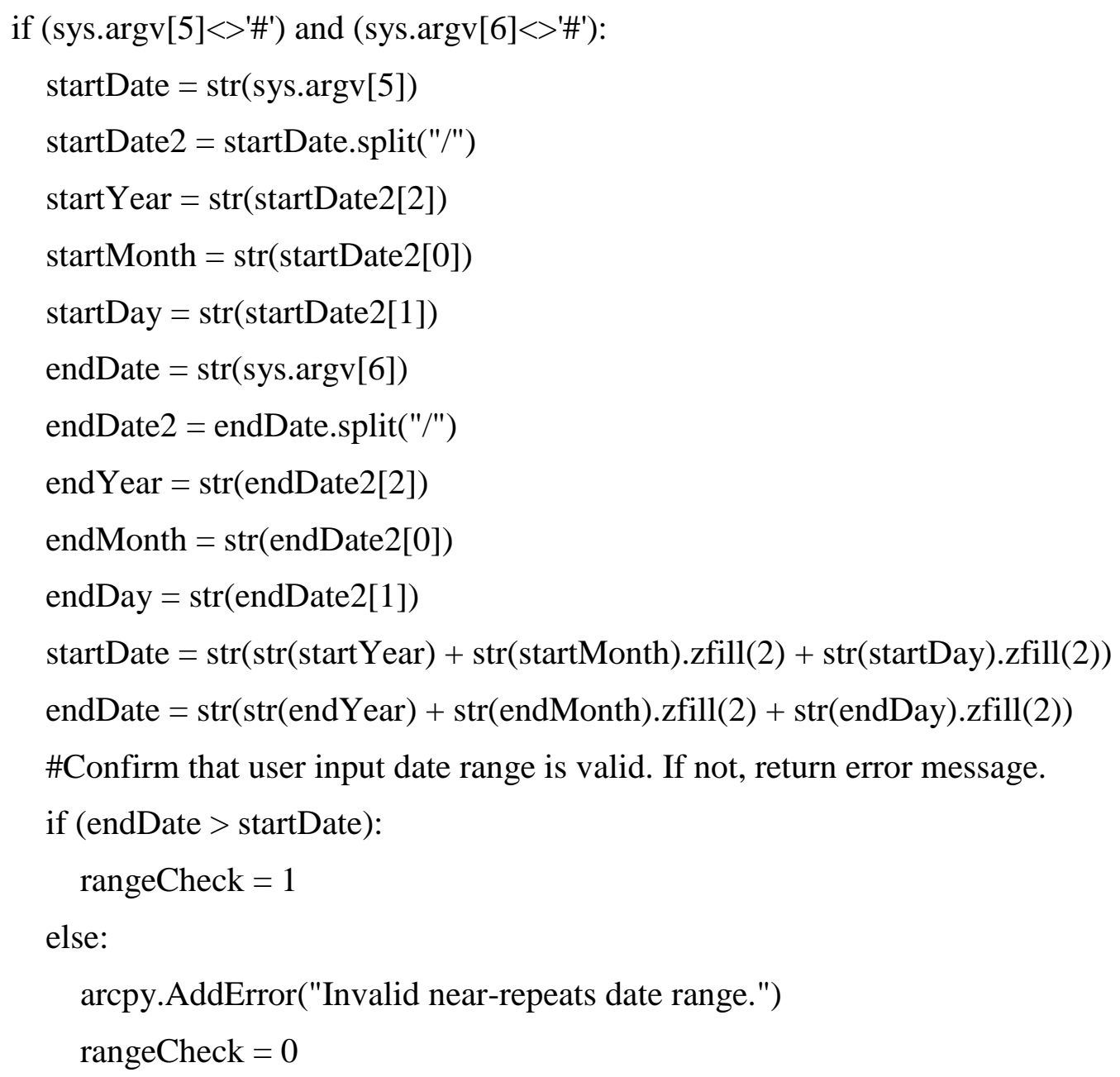




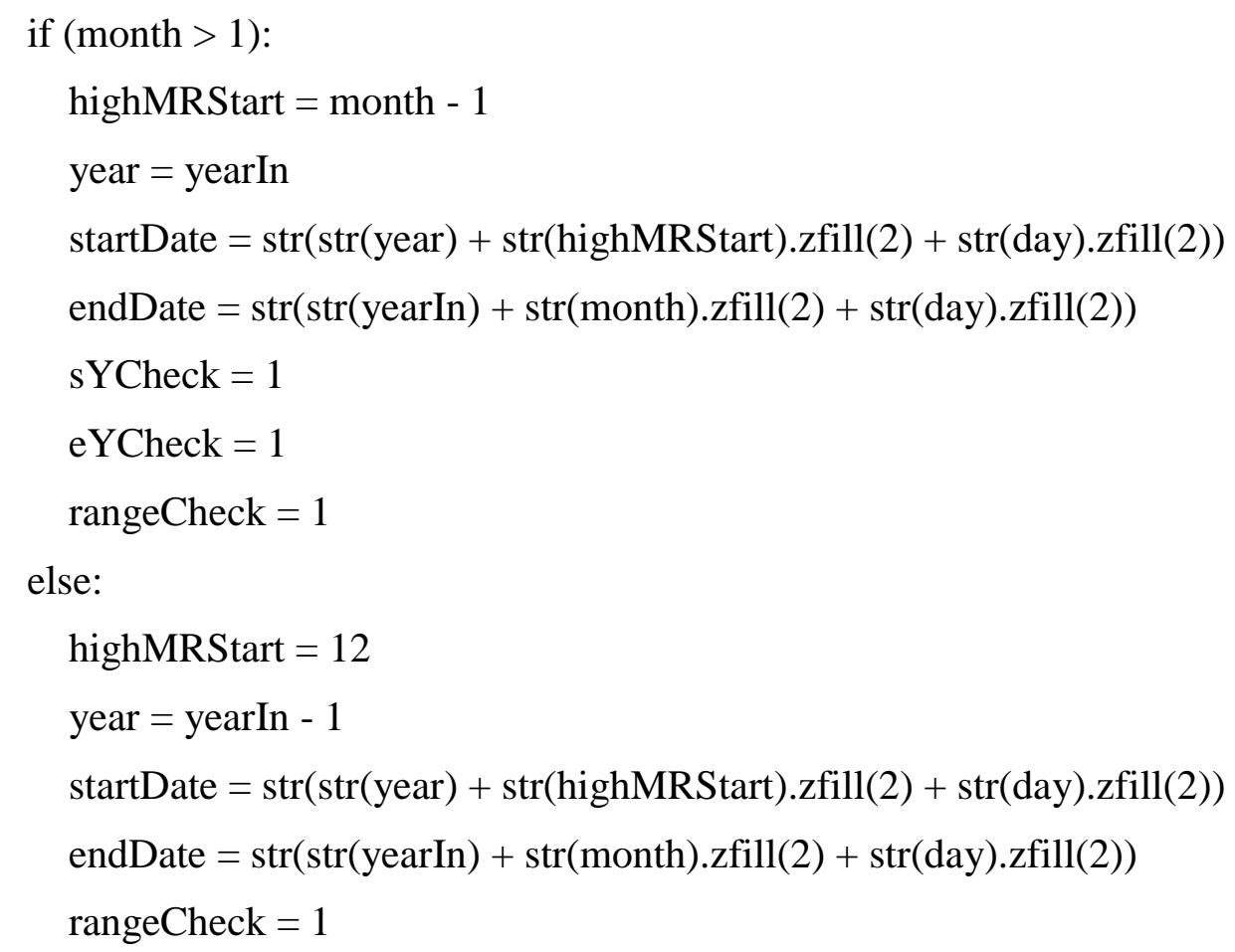

\#Parse 1 month risk near repeat for query

formatStartDate $=\operatorname{str}(\operatorname{str}(\operatorname{startDate})+$ " 00:00:00")

formatEndDate $=\operatorname{str}(\operatorname{str}($ endDate $)+$ " 00:00:00")

else:

repeatRisk $\mathrm{R}=0$

delRepeat $=0$

\#If the user has selected to include near-repeats, and the range is valid:

if (sys.argv[4]<>'\#') and (rangeCheck ==1):

\#Convert incidents into layer for attribute selection

incidents = "in_memoryllincidents"

arcpy.CopyFeatures_management("C:IUserslsara_goetz\Documents\MIP\RTMTool\RT MDatabase.gdb\Incidents", incidents)

grid = "in_memoryllgrid" 


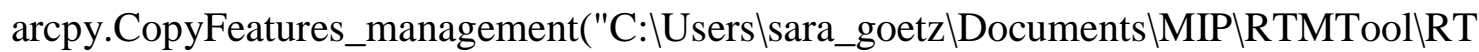

MDatabase.gdb\RedlandsGrid", grid)

$$
\begin{aligned}
& \text { gridLyr = "in_memoryl|gridLyr" } \\
& \text { arcpy.MakeFeatureLayer_management(grid, gridLyr) } \\
& \text { incidentLyr = "in_memoryllincidentLyr" } \\
& \text { bufferRepeat = "in_memoryllbufferRepeat" }
\end{aligned}
$$

\#Group like crimes for assaults and vehicle related crimes

if (crimeType $==$ "Assault"):

crimeType = "\'Assault - Felonyl' OR \"CVLEGEND01\" = \'Assault -

Misdemeanorl' OR \"CVLEGEND01\" = \'Assault - DV $\backslash "$

elif (crimeType $==$ "Vehicle Related"):

crimeType = "I'Auto Theftl' OR I"CVLEGEND01।" = \'Burglary - Vehiclel' OR

।"CVLEGEND01।" = 'Theft - Vehcilel' OR \"CVLEGEND01।" = \'Vehiclel'"

\#Query incident database for specified crime types within the specified date range

crimeField = "CVLEGEND01"

$\operatorname{midDt}=$ "midDt"

repeatQuery = "\" + crimeField + "\" = " + crimeType + "' AND " + "\" + midDt + "|" >= "' + formatStartDate + "' AND " + "\"" + midDt + "\"<= "' + formatEndDate + "'"

arcpy.MakeFeatureLayer_management(incidents, incidentLyr, repeatQuery)

rows $=$ int(arcpy.GetCount_management(incidentLyr).getOutput(0))

if rows $>0$ :

\#Select and buffer burglaries that are returned by the query arcpy.Buffer_analysis(incidentLyr, bufferRepeat, "660 Feet", "FULL", "ROUND", "ALL")

\#Convert in_memory buffer variable to in_memory layer for use in Select Layer by Location tool

bufRepeatLyr = "in_memoryllbufRepeatLyr"

arcpy.MakeFeatureLayer_management(bufferRepeat, bufRepeatLyr) 
\#Select grid cells that intersect with the near repeat buffer layer, populate "Value" with 1

arcpy.SelectLayerByLocation_management(gridLyr, "INTERSECT", bufRepeatLyr)

arcpy.CalculateField_management(gridLyr, "Value", "1")

arcpy.SelectLayerByAttribute_management(gridLyr, "CLEAR_SELECTION")

\#Convert near repeats gridLyr to raster

arcpy.PolygonToRaster_conversion(gridLyr, "Value",

"C:/Users/sara_goetz/Documents/MIP/RTMTool/RTMDatabase.gdb/repeatRiskR", "', "", "100")

\#Store near repeats raster as repeatRiskR

repeatRiskR =

Raster("C:/Users/sara_goetz/Documents/MIP/RTMTool/RTMDatabase.gdb/repeatRiskR ")

$$
\text { delRepeat }=1
$$

else:

$$
\begin{aligned}
& \text { repeatRiskR }=0 \\
& \text { delRepeat }=0
\end{aligned}
$$

\#If near repeats are not included in the model, assign a value of 0 else:

$$
\begin{aligned}
& \text { repeatRiskR }=0 \\
& \text { delRepeat }=0
\end{aligned}
$$

\#Processing arrestee home addresses, if selected

if sys.argv[8]<>'\#':

arcpy.AddMessage("Processing recent arrestees...")

\#If the user has input specific date range, use these as query inputs. If not, use default. if (sys.argv[9]<>'\#') and (sys.argv[10]<>'\#'):

$$
\text { startDate }=\operatorname{str}(\text { sys.argv[9] })
$$




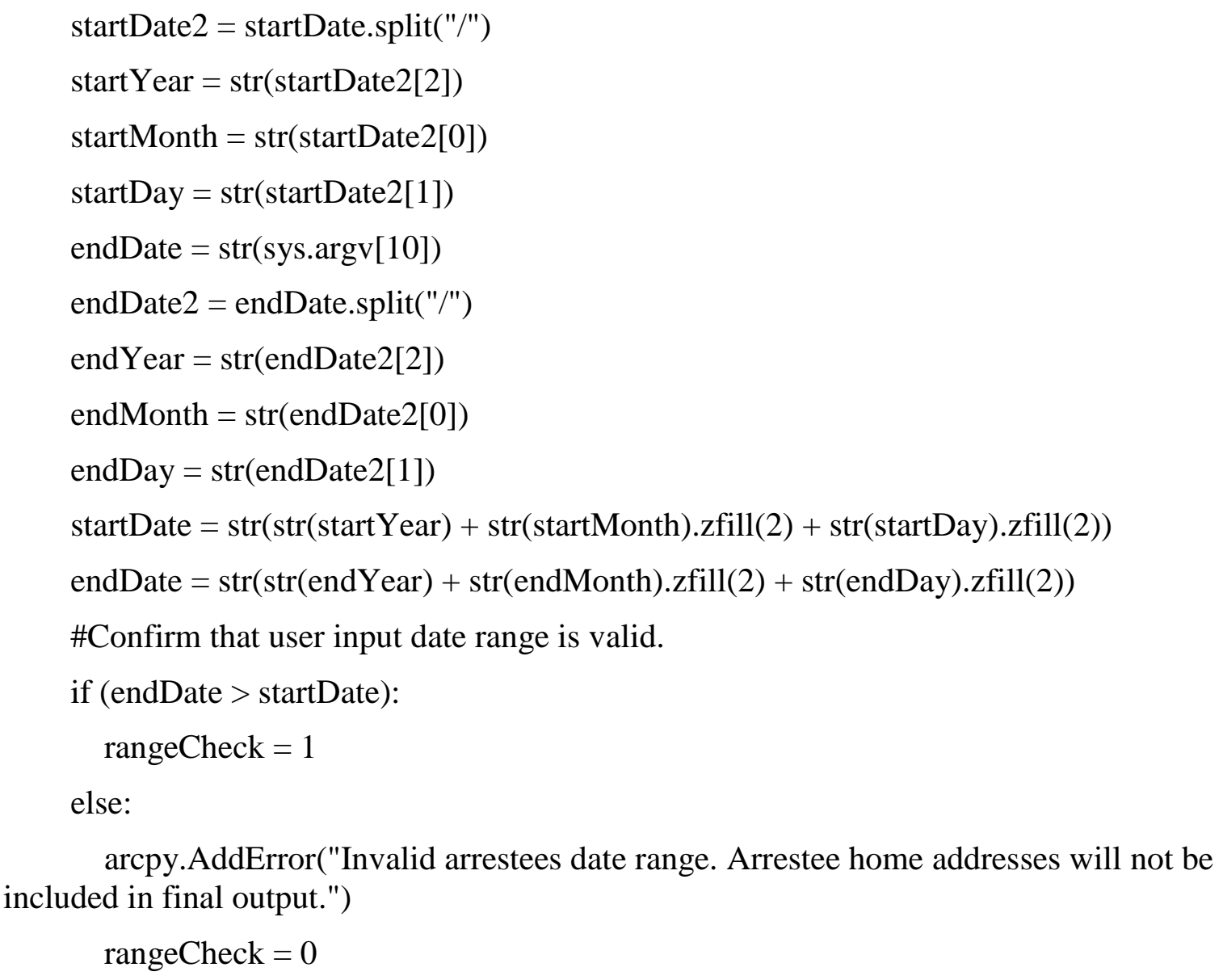
included in final output.")

rangeCheck $=0$

\#If no user-input date range, use system default

else:

if (month > 1):

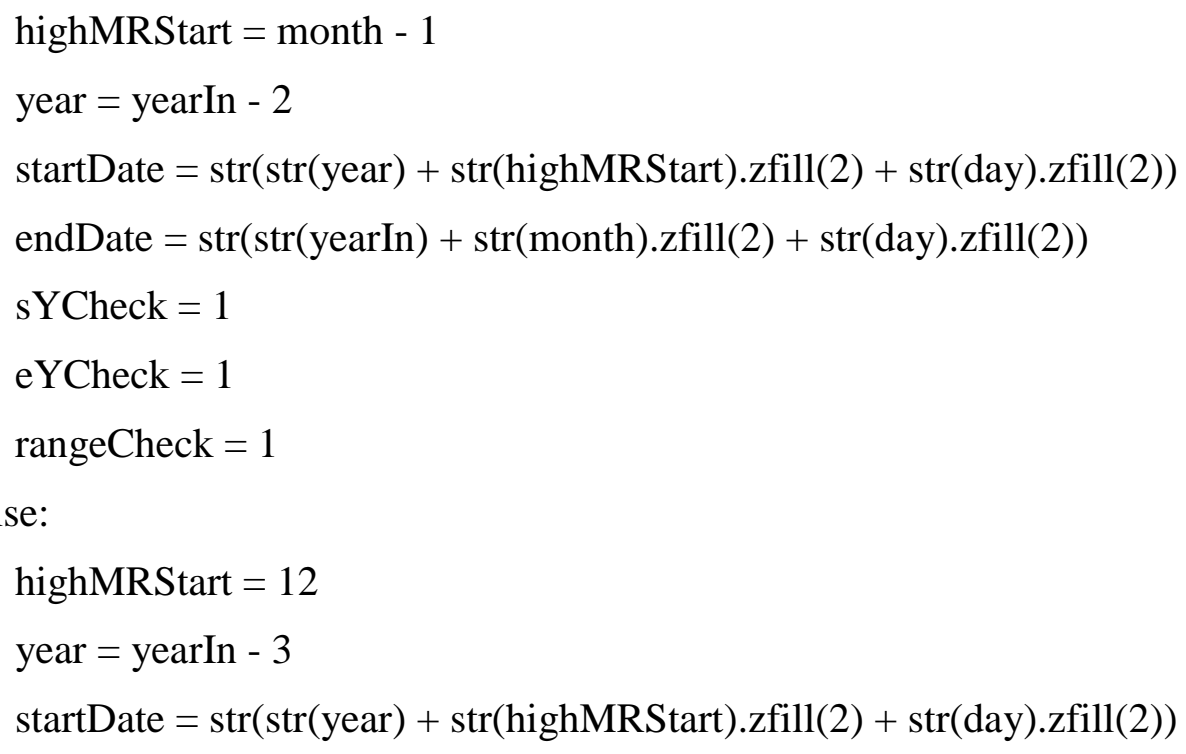


endDate $=\operatorname{str}(\operatorname{str}($ yearIn $)+\operatorname{str}($ month $) \cdot z f i l l(2)+\operatorname{str}($ day $) \cdot z f i l l(2))$

rangeCheck $=1$

\#Parse 1 month risk near repeat for query

formatStartDate $=\operatorname{str}(\operatorname{str}(\operatorname{startDate})+$ " 00:00:00")

formatEndDate $=\operatorname{str}(\operatorname{str}($ endDate $)+$ " 00:00:00")

else:

arrestee $\mathrm{R}=0$

delArrestee $=0$

if (sys.argv[8]<>'\#') and (rangeCheck ==1):

\#Create in_memory variables and copy features needed to process recent arrestee home addresses

arrestees = "in_memoryllarrestees"

arcpy.CopyFeatures_management("C:IUserslsara_goetz\Documents\MIP\RTMTool\RT MDatabase.gdblStaticarrests", arrestees)

arresteeLyr = "in_memoryllarresteesLyr"

bufArrestees = "in_memoryllbufArrestees"

\#Set up query for home addresses of arrestees

ArrestDt $=$ "ArrestDt"

arresteeQuery = "\"" + ArrestDt + "\" >= " + formatStartDate + "' AND " + "\"" + ArrestDt + "\"<= "' + formatEndDate + "'"

arcpy.MakeFeatureLayer_management(arrestees, arresteeLyr, arresteeQuery)

\#Create kernel density surface of arrestee home addresses for those arrested within the past two years

arcpy.CheckOutExtension("Spatial")

bufArrestees = KernelDensity(arresteeLyr, "NONE", 100, 1500, "SQUARE_MILES") 
\#Normalize arrestee kernel density to values between 0 and 1 (the same as the other inputs)

minResultA = arcpy.GetRasterProperties_management(bufArrestees, "MINIMUM")

$\min \mathrm{A}=$ float $(\operatorname{minResult} \mathrm{A} \cdot \operatorname{getOutput}(0))$

maxResultA = arcpy.GetRasterProperties_management(bufArrestees, "MAXIMUM")

$\max \mathrm{A}=$ float $(\max R e s u l t \mathrm{~A} \cdot \operatorname{getOutput}(0))$

normArr $=($ bufArrestees $-\min A) /(\max A-\min A)$

normArr.save("C:/Users/sara_goetz/Documents/MIP/RTMTool/RTMDatabase.gdb/arrest eeR")

\#Store arrestee homes raster as arresteeR

arrestee $\mathrm{R}=$

Raster("C:/Users/sara_goetz/Documents/MIP/RTMTool/RTMDatabase.gdb/arresteeR")

delArrestee $=1$

\#If arrestee home addresses are not included in the model, assign a value of 0

else:

arrestee $\mathrm{R}=0$

delArrestee $=0$

\#Check out the Spatial Analyst extension

arcpy.CheckOutExtension("Spatial")

\#Calculate risk values

arcpy.AddMessage("Calculating risk values...")

outRaster $=(($ factor $1 *$ factor $1 \mathrm{~W})+($ factor $2 \mathrm{In} *$ factor $2 \mathrm{~W})+($ factor $3 \mathrm{In} *$ factor $3 \mathrm{~W})+$ $($ factor $4 \mathrm{In} *$ factor $4 \mathrm{~W})+($ factor5In $*$ factor $5 \mathrm{~W})+($ factor6In $*$ factor6W) + (repeatRiskR $*$ repeatRiskW $)+($ arrestee $\mathrm{R} *$ arresteeRiskW) $) *$ filter

\#Normalize risk values

arcpy.AddMessage("Normalizing risk values...")

minResult = arcpy.GetRasterProperties_management(outRaster, "MINIMUM")

$\min =$ float $(\operatorname{minResult} \cdot \operatorname{getOutput}(0))$ 
maxResult $=$ arcpy.GetRasterProperties_management(outRaster, "MAXIMUM")

$\max =$ float $(\max R e s u l t . g e t O u t p u t(0))$

normRaster $=(($ outRaster $-\min ) /(\max -\min )) * 10$

\#Save output raster

normRaster.save(output)

\#Check the Spatial Analyst extension back in

arcpy.CheckInExtension("Spatial")

\#Delete temporary rasters

if (delRepeat >0):

arcpy.Delete_management("C:/Users/sara_goetz/Documents/MIP/RTMTool/RTMDataba se.gdb/repeatRiskR")

if (delArrestee > 0):

arcpy.Delete_management("C:/Users/sara_goetz/Documents/MIP/RTMTool/RTMDataba se.gdb/arresteeR") 


\section{Appendix B. Detailed Chi-square Test Results}

\section{Lighting}

The lighting factor is slightly different from the other factors. It was expected that there would be higher percentages of residential burglaries where it is dark (which is true) however this percentage is not greater than the percentage of cells that are considered dark with no reported residential burglaries. Table B-1 demonstrates this.

Table B-1: Proximity to Lighting * Residential Burglary Crosstabulation

\begin{tabular}{|c|c|c|c|}
\hline \multicolumn{2}{|c|}{} & \multicolumn{2}{c|}{ Residential Burglaries } \\
\cline { 3 - 4 } & No (Dark) & $65.9 \%$ & Yes \\
\hline \multirow{2}{*}{ Proximity to Lighting } & Yes (Light) & $34.1 \%$ & $60.9 \%$ \\
\cline { 3 - 4 } & Yes & $39.1 \%$ \\
\hline
\end{tabular}

$\mathrm{p}<0.01$

These results were reasonable considering the scale at which the factor was modeled. For this study, the city of Redlands was divided into 100 foot by 100 foot grid cells, totaling just over 100,000 cells (approximately 37,000 when clipped to residential areas only, as these test data were). Perhaps if the study area was smaller and more focused on only the urban city area the lighting data, which originally consisted of points indicating the location of light poles, could be displayed and analyzed more accurately at a larger scale. At the small scale required for study of the entire city, the city was distinctly divided between generally lighted urban areas and dark rural areas. Because urban areas typically experience more crime, it appeared as that most of the crime in Redlands was occurring in well-lit areas. This factor was not considered for the final model.

\section{Proximity to Schools}

Although previous research indicated high schools as being correlated to residential burglary, the client suggested using both middle and high schools for Redlands. Middle and high schools were tested, and in a second test colleges were included. Tables B-2 and B-3 are simplified versions of these tables.

Table B-2: Proximity to Middle Schools, High Schools, and Colleges * Residential Burglary Crosstabulation

\begin{tabular}{|c|c|c|c|}
\hline \multicolumn{2}{|c|}{} & \multicolumn{2}{|c|}{ Residential Burglaries } \\
\cline { 3 - 4 } \multicolumn{2}{|c|}{} & No & Yes \\
\hline $\begin{array}{c}\text { Proximity to Schools } \\
\text { (including Colleges) }\end{array}$ & No & $82.8 \%$ & $75.5 \%$ \\
\cline { 2 - 4 } & Yes & $17.2 \%$ & $24.5 \%$ \\
\hline
\end{tabular}

$\mathrm{p}<0.01$

Proximity to middle schools, high schools, and colleges was significantly correlated to residential burglaries, and was considered as a factor in the final model because the percent of residential burglaries within the school proximity factor buffer $(24.5 \%)$ was 
greater than the percentage of cells within the same area that had no burglaries (17.2\%). This interpretation of the schools factor was considered for use in the model because the differences in percentages noted above are greater than those found with only middle and high schools (see Table B-3).

Table B-3: Proximity to Middle and High Schools * Residential Burglary Crosstabulation

\begin{tabular}{|c|c|c|c|}
\hline \multicolumn{2}{|c|}{} & \multicolumn{2}{c|}{ Residential Burglaries } \\
\cline { 3 - 4 } \multicolumn{2}{|c|}{} & No & Yes \\
\hline $\begin{array}{c}\text { Proximity to Schools } \\
\text { (excluding Colleges) }\end{array}$ & No & $87.1 \%$ & $84.2 \%$ \\
\cline { 2 - 4 } & Yes & $12.9 \%$ & $15.8 \%$ \\
\hline
\end{tabular}

$\mathrm{p}<0.05$

The proximity to schools factor operationalized to exclude colleges was also statistically significantly correlated to residential burglaries, and would have been acceptable to include in the model as the percentage of cells that experienced residential burglaries and were within the schools buffer is greater than the percentage of cells within the schools buffer that did not experience residential burglaries.

\section{Proximity to Groves or Vacant Lots}

The proximity to wooded areas or vacant lots and residential burglaries crosstabulation results were not as expected. According to the literature, areas adjacent to vacant lots experience higher rates of residential burglaries. This was found to not be true for Redlands. Table B-4 shows the results of the crosstabulation.

Table B-4: Proximity to Groves Areas or Vacant Lots * Residential Burglary Crosstabulation

\begin{tabular}{|c|c|c|c|}
\hline \multicolumn{2}{|c|}{} & \multicolumn{2}{c|}{ Residential Burglaries } \\
\cline { 3 - 4 } \multicolumn{2}{|c|}{} & No & Yes \\
\hline $\begin{array}{c}\text { Proximity to Wooded Areas } \\
\text { or Vacant Lots }\end{array}$ & No & $7.9 \%$ & $12.7 \%$ \\
\cline { 2 - 4 } & Yes & $92.1 \%$ & $87.3 \%$ \\
\hline
\end{tabular}

The percentages of cells where burglaries occurred and were within the proximity to groves and vacant land buffer were less than the percentages for those areas which were in the buffer but did not experience a residential burglary. This outcome could be a byproduct of the suburban nature of Redlands, as opposed to the urban environments most literature on residential burglaries refers to. This is not a strong factor and was not included for consideration in the final model.

\section{Proximity to Arrestees}

The proximity to arrestee home addresses factor was found to be statistically significantly correlated to residential burglaries. The percent of residential burglaries occurring in each category remained higher than in cells that did not experience residential burglaries with 
the exception of the category that contained the lowest number of arrestees. Table B-5 shows the vast differences between these percentages.

Table B-5: Proximity to Arrestees * Residential Burglary Crosstabulation

\begin{tabular}{|c|c|c|c|}
\hline \multicolumn{2}{|c|}{} & \multicolumn{2}{c|}{ Residential Burglaries } \\
\cline { 3 - 4 } & $0,1, \& 2$ & No & Yes \\
\hline \multirow{2}{*}{ Proximity to Arrestees } & $0, \&$ ) & $98.8 \%$ & $93.5 \%$ \\
\cline { 2 - 4 } & 3 (High) & $1.2 \%$ & $6.5 \%$ \\
\hline
\end{tabular}

$\mathrm{p}<0.01$

When percent within proximity to arrestees was examined, there was a clear increase in the density of residential burglary occurrences as the density of previous arrestee's homes increased. Proximity to arrestees' homes is one of the dynamic factors that may be included in the model. The densities were not categorized for use in the final model, but were instead normalized within the script.

\section{Median Income}

The income factor and residential burglary are statistically significantly correlated and the relationship was as expected; residential burglary was expected to be higher in areas with lower incomes. The factor also passed the percentages test. Within areas with the lowest income category, residential burglary percentages were higher than the percentages of cells that had not experienced a residential burglary. Table B-6 shows simplified results of the crosstabulation output.

Table B-6: Income * Residential Burglary Crosstabulation

\begin{tabular}{|c|c|c|c|}
\hline \multicolumn{2}{|c|}{} & \multicolumn{2}{c|}{ Residential Burglaries } \\
\cline { 3 - 4 } & & No & Yes \\
\hline \multirow{2}{*}{ Income } & 1 (Low) & $25.1 \%$ & $40.4 \%$ \\
\cline { 2 - 4 } & $2 \& 3$ & $74.9 \%$ & $59.6 \%$ \\
\hline
\end{tabular}

$\mathrm{p}<0.01$

The income factor was categorized for statistical testing, but normalized median incomes for each cell as reported by the US Census were used to create the final raster factor.

\section{Proximity to Pawn Shops}

Proximity to pawn shops was a factor identified through the literature review. The factor was found to be statistically significantly correlated to residential burglaries through the Chi-square test, and also passed the percentages test. Table B-7 shows the results for the proximity to pawn shops factor. 
Table B-7: Proximity to Pawn Shops * Residential Burglary Crosstabulation

\begin{tabular}{|c|c|c|c|}
\hline \multicolumn{2}{|c|}{} & \multicolumn{2}{c|}{ Residential Burglaries } \\
\cline { 3 - 4 } Proximity to Pawn Shops & No & No & Yes \\
\cline { 2 - 4 } & Yes & $85.7 \%$ & $76.9 \%$ \\
\hline \multirow{2}{*}{ Pey } & $14.3 \%$ & $23.1 \%$ \\
\hline
\end{tabular}

$\mathrm{p}<0.01$

\section{Proximity to Thoroughfares}

Proximity to thoroughfares was found to be statistically significantly correlated to residential burglaries and passed the percentages test. Table B-8 shows the results for the proximity to thoroughfares and residential burglary crosstabulation.

Table B-8: Proximity to Thoroughfares * Residential Burglary Crosstabulation

\begin{tabular}{|c|c|c|c|}
\hline & \multicolumn{2}{|c|}{ Residential Burglaries } \\
\hline & & No & Yes \\
\hline \multirow{2}{*}{ Proximity to Thoroughfares } & No & $76.6 \%$ & $60.6 \%$ \\
\hline & Yes & $23.4 \%$ & $39.4 \%$ \\
\hline
\end{tabular}

$\mathrm{p}<0.01$

When operationalizing the proximity to major thoroughfares factor, the actual thoroughfares and the areas immediately adjacent to them (within 132 feet) were assigned a risk value of zero to in order to account for the impossibility of a residential burglary occurring on a roadway. The Redlands incident data were plotted at an offset to the location along the road to which an address corresponds, so cutting out the actual road area made sense for the given incident data.

\section{Population Density}

Population density produced results similar to what was expected. Each of the within column percentages for cells with residential burglary were higher than those in which no residential burglary occurred in the densest category, and the factor was statistically significantly correlated. Table B-9 shows the within column percentages in the crosstabulation output table.

Table B-9: Population Density * Residential Burglary Crosstabulation

\begin{tabular}{|c|c|c|c|}
\hline \multicolumn{2}{|c|}{} & \multicolumn{2}{c|}{ Residential Burglaries } \\
\cline { 3 - 4 } \multicolumn{2}{|c|}{} & No & Yes \\
\hline \multirow{2}{*}{ Population Density } & $1,2, \& 3$ & $90.9 \%$ & $80.3 \%$ \\
\cline { 2 - 4 } & 4 (High) & $9.1 \%$ & $19.7 \%$ \\
\hline
\end{tabular}

$\mathrm{p}<0.01$ 
The highest percentages of burglary occurrences were not in the most densely populated areas. This makes sense, as the most densely populated areas have increased guardianship from neighbors, and are likely apartment complexes which may not be as attractive a target as a single family house. Examining the within row percentages, however, the percentages of burglaries within each class increases dramatically as population density increases. While the percentage of burglaries occurring in high density areas is lower than the two mid-range density categories, when filtered by row, it is actually a much higher percentage (nearly double that of the two mid-range densities). This is because the number of cells with the highest density is significantly less than the other classes. Less burglaries are occurring, but within a much smaller area, making the relationship between population density and residential burglaries much more linear than expected. The final population density factor was normalized between zero and one from the raw population density data, not the categorized values used in the Chi-square test.

\section{Household Density}

The household density factor produced similar results to what was expected. The factor is significant, the percentage of cells that experienced residential burglary and were within the highest household density category was greater than the percentage of cells that did not experience residential burglary but were within the highest household density category. Table B-10 shows the household density crosstabulation table.

Table B-10: Household Density * Residential Burglary Crosstabulation

\begin{tabular}{|l|c|c|c|}
\hline \multicolumn{2}{|c|}{} & \multicolumn{2}{c|}{ Residential Burglaries } \\
\cline { 3 - 4 } \multicolumn{2}{|c|}{} & No & Yes \\
\hline \multirow{2}{*}{ Household Density } & $1,2, \& 3$ & $97.8 \%$ & $97.0 \%$ \\
\cline { 2 - 4 } & 4 (High) & $2.2 \%$ & $3.0 \%$ \\
\hline
\end{tabular}

$\mathrm{p}<0.01$

This factor was not included in the final model, and was not included in the final database because it was very similar to the population density factor, yet did not perform as well as population density. The difference between the percentage of cells that were in the highest population density category and experienced residential burglaries and the percentage of cells that were in the highest population density category but did not experience residential burglary was greater than the difference amongst the same combination of cells for household density. The population density factor for the same categories displayed a much more linear relationship. 